\title{
Si/Ag/C Nanohybrids with in situ Incorporation of Super-Small Silver Nanoparticles: Tiny Amount, Huge Impact
}

Shanshan Yin ${ }^{1,}{ }^{2 \dagger}$, Dong Zhao ${ }^{3 \dagger}$, Qing $\mathrm{Ji}^{1,}{ }^{4}$, Yonggao Xia ${ }^{1}$, Senlin Xia ${ }^{5}$, Sophia Haussener ${ }^{6}$, Xinming Wang ${ }^{1}$, Meimei Wang ${ }^{1}$, Jianzhen Ban ${ }^{1,7}$, Yi Zhang ${ }^{1,2}$, Ezzeldin Metwalli ${ }^{5}$, Xiaoyan Wang $^{1,8}$, Ying Xiao ${ }^{1}$, Xiuxia Zuo ${ }^{1,8}$, Shuang Xie ${ }^{1,8}$, Kai Fang ${ }^{1,7}$, Suzhe Liang ${ }^{1,2}$, Luyao Zheng ${ }^{1,8}$, Bao Qiu ${ }^{1}$, Zhaohui Yang ${ }^{9}$, Yichao Lin ${ }^{1}$, Liang Chen $^{1}$, Cundong Wang ${ }^{2}$, Zhaoping Liu ${ }^{1}$, Jin Zhu ${ }^{1}$, Peter Müller-Buschbaum ${ }^{5}$, and Ya-Jun Cheng ${ }^{1,10^{*}}$

1. Ningbo Institute of Materials Technology and Engineering, Chinese Academy of Science, 1219 Zhongguan West Rd, Ningbo, 315201, P. R. China

2. North University of China, Shanglan Rd, Taiyuan, Shanxi Province, 030051, P. R. China

3. Max-Planck Institute for Solid State Research, Heisenbergstrasse 1, 70569 Stuttgart, Germany

4. The University of Nottingham Ningbo China, 199 Taikang East Road, Ningbo, 315100, P. R. China

5. Physik-Department, Lehrstuhl für Funktionelle Materialien, Technische Universität München, James-Franck-Str. 1, 85748 Garching, Germany

6. Laboratory of Renewable Energy Science and Engineering, Ecole Polytechnique Fédérale de Lausanne (EPFL), Station 9, 1015 Lausanne, Switzerland

7. Nano Science and Technology Institute, University of Science and Technology of China, 166 Renai Rd, Suzhou, 215123, P.R. China

8. University of the Chinese Academy of Sciences, 19 A Yuquan Rd, Shijingshan District, Beijing, 
100049, P. R. China

9. Center for Soft Condensed Matter Physics and Interdisciplinary Research, Soochow University, Suzhou 215006, P. R. China

10. Department of Materials, University of Oxford, Parks Rd, OX1 3PH, Oxford, UK

$\uparrow$ Shanshan Yin and Dong Zhao contribute equally to this work.

Email address: chengyj@nimte.ac.cn

\section{ABSTRACT}

Silicon ( $\mathrm{Si}$ ) has been regarded as one of the most promising anodes for next generation lithium ion batteries (LIBs) due to its exceptional capacity, appropriate voltage profile, and reliable operation safety. However, poor cyclic stability and moderate rate performance have been critical drawbacks to hamper the practical application of Si-based anodes. It has been one of the central issues to develop new strategies to improve the cyclic and rate performance of the Si-based lithium-ion battery anodes. In this work, super-small metal nanoparticles (2.9 $\mathrm{nm}$ in diameter) are in situ synthesized and homogeneously embedded in the in situ formed nitrogen-doped carbon matrix, as demonstrated by the $\mathrm{Si} / \mathrm{Ag} / \mathrm{C}$ nanohybrid, where epoxy resin monomers are used as solvent and carbon source. With tiny amount of silver (2.59 \% by mass), the $\mathrm{Si} / \mathrm{Ag} / \mathrm{C}$ nanohybrid exhibits superior rate performance compared to the bare $\mathrm{Si} / \mathrm{C}$ sample. Systematic structure characterization and electrochemical performance tests of the $\mathrm{Si} / \mathrm{Ag} / \mathrm{C}$ nanohybrids have been performed. The mechanism for the enhanced rate performance is investigated and elaborated. The temperature dependent $I-V$ behavior of the $\mathrm{Si} / \mathrm{Ag} / \mathrm{C}$ nanohybrids with tuned silver contents is measured. Based on the model, it is found that the super-small silver nanoparticles mainly increase charge carrier mobility instead of the charge carrier density in the $\mathrm{Si} / \mathrm{Ag} / \mathrm{C}$ nanohybrids. The evaluation of the total electron transportation length provided 
by the silver nanoparticles within the electrode also suggests significantly enhanced charge carrier mobility. The existence of tremendous amounts of super-small silver nanoparticles with excellent mechanical properties also contribute to the slightly improved cyclic stability compared to simple $\mathrm{Si} / \mathrm{C}$ anodes.

KEYWORDS: silicon; silver nanoparticles; nanohybrid; lithium-ion battery; anode; epoxy resin; super-small 
Efficient and durable energy storage devices are essential for volatile and fluctuating renewable energy sources. ${ }^{1-4}$ Rechargeable lithium-ion batteries (LIBs) with high power and energy density have attracted significant attention from both industry and academia as a powerful energy storage media. They have been widely used in electric vehicles (EVs), portable electronic devices, and smart grid systems. ${ }^{5-7}$ These applications have spurred increasing demand for developing new electrode materials to achieve high energy and/or power density, long cycle life, fast charge rate, and low production cost. Silicon ( $\mathrm{Si}$ ) has emerged as a promising candidate for next-generation LIB anodes due to its unparalleled theoretical capacity compared to commercial graphite (4200 $\mathrm{mAh} \mathrm{g}^{-1}$ vs. $372 \mathrm{mAh} \mathrm{g}^{-1}$ ), proper voltage profile, and enhanced operation safety. ${ }^{8-19}$ However, the intrinsic drawback of huge volume change during lithiation/delithiation cycles leads to fracture of $\mathrm{Si}$, pulverization of electrodes, and continuous formation/rupture of solid electrolyte interphase (SEI).$^{20-23}$ All of these processes lead to very poor cyclic stability. It has been recognized as one of the most critical neck-points hampering the practical application of the Si-based LIBs anodes. ${ }^{24}$ Besides the poor cyclic stability, the rate performance of $\mathrm{Si}$ anodes also needs to be improved. ${ }^{13}$, ${ }^{25} \mathrm{Si}$ possesses rather low intrinsic electron conductivity because of its semiconductor nature. Various strategies have been developed to resolve these problems including particle size reduction to the nanoscale level, ${ }^{20,26-27}$ compositing $\mathrm{Si}$ with conductive buffer media such as, $\mathrm{Cu}^{28} \mathrm{Ag},{ }^{29}$ and carbonaceous material, ${ }^{19,24,30-33}$ and constructing hierarchical architectures. ${ }^{18,34}$ Despite of the success of the performance improvement based on the strategies addressed above, the issue of mass loading density of Si has been largely ignored, which is vital for practical applications regarding total energy/power density output. ${ }^{35-36}$ 
Metal exhibits excellent mechanical property and superior electron conductivity. It has been recognized as one of the most promising buffer media to improve the performance the Si-based anodes. $^{37-47}$ Normally quite large amount of metal is needed for surface modification of the silicon. $^{39,42-43,46-47}$ Nevertheless, excessive incorporation of metal species tends to reduce the overall capacity, increase the cost, and make the coating process complicated and non-feasible. It is essential to develop new strategies to use small amount of metal species, while effectively improve the electrochemical performance of the silicon based anode. ${ }^{48}$ Here as a demonstration of our concept, we present the in situ synthesis and homogeneous embedding of super-small silver nanoparticles into the silicon/carbon anode. With this strategy, the rate performance is significantly improved and the cyclic stability is slightly enhanced as well. This strategy is in principle universally applicable to other metal system such as copper, and iron. Even though silver has been used previously as a buffer medium to the silicon based anode, the size of the silver particles is large (normally above $20 \mathrm{~nm}$ ) and decent amount of silver is therefore needed. ${ }^{43,46}$ Here the average size of the as-synthesized silver nanoparticles in this work is significantly reduced to well below 5 $\mathrm{nm}$, which has been rarely used to modify the silicon anode. ${ }^{29,49-50}$ By combing the simultaneous in situ synthesis of silver and composition with carbon matrix, it is possible to incorporate the super-small silver nanoparticles into the $\mathrm{Si} / \mathrm{C}$ composite homogeneously. ${ }^{51}$ The super-small size feature and homogeneous dispersion of the silver nanoparticles significantly improve the performance of Si-based anodes with tiny amount of silver.

Recently, a strategy was developed by our group to synthesize $\mathrm{TiO}_{2} / \mathrm{C}$ and $\mathrm{SiOC} / \mathrm{C}$ nanohybrid LIB anodes, where super-small $\mathrm{TiO}_{2}$ or SiOC nanoparticles were synthesized and homogeneously embedded in a continuous carbon matrix. ${ }^{52-55}$ Thermosetting methacrylate monomers were used as 
solvent and carbon source. The precursor of $\mathrm{TiO}_{2}$ (Titanium tetraisopropoxide, TTIP) or SiOC (methacryloxy propyl trimethoxy silane, MPTMS) was dissolved in the resin monomer solution at molecular level. Through photo polymerization, the TTIP or MPTMS was integrated into the methacrylate cross-linking network via covalent bonding and/or hydrogen bonding interaction. The calcination process converted the thermosetting polymer into a carbon matrix, while transforming the precursor into $\mathrm{TiO}_{2}$ or $\mathrm{SiOC}$ simultaneously. Because there is almost no melting process for the thermosetting polymer during high temperature calcination, the nucleation, growth, agglomeration, and crystallization of the inorganic nanoparticles were significantly hindered. As a result, super-small $\mathrm{TiO}_{2}$ or SiOC nanoparticles with very poor crystallinity were in situ synthesized and homogeneously embedded in the carbon matrix. Due to the unique structure feature and poor crystallinity of the inorganic particles, unusual electrochemical performance as LIB anodes was observed regarding the $\mathrm{TiO}_{2} / \mathrm{C}$ and $\mathrm{SiOC} / \mathrm{C}$ nanohybrids. ${ }^{52-55}$

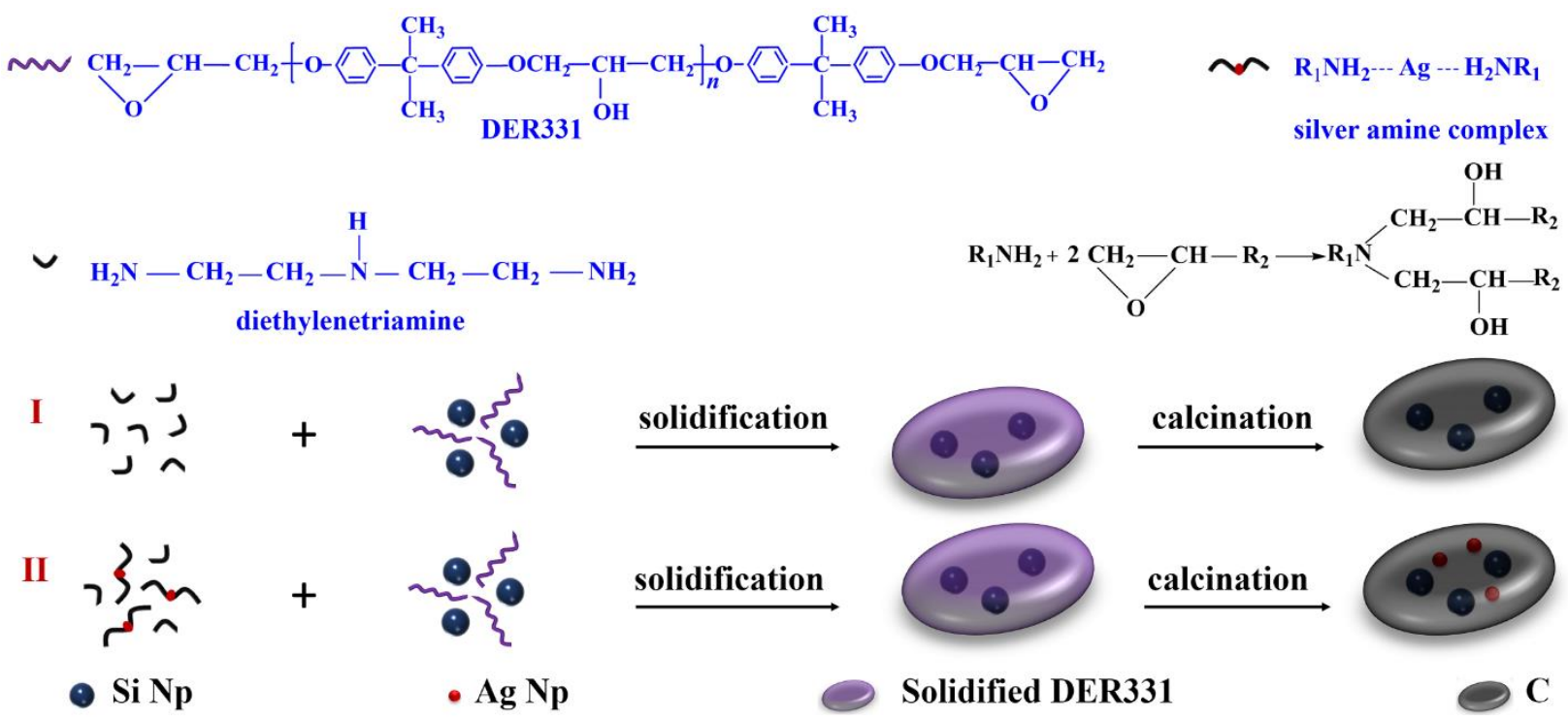

Scheme 1. Schematics of the precursor molecular structure, fabrication process, and structure of the $\mathrm{Si} / \mathrm{Ag} / \mathrm{C}$ nanohybrids. In route I only Si nanoparticles are embedded in the carbon matrix. In route II in addition also silver $(\mathrm{Ag})$ nanoparticles are embedded together with Si nanoparticles. 
Inspired by our previous research work, we present an approach to synthesize $\mathrm{Si} / \mathrm{Ag} / \mathrm{C}$ nanohybrid LIB anodes, where super-small silver nanoparticles are in situ synthesized and homogeneously embedded in a carbon matrix (Scheme 1). Epoxy resin monomers (DER 331) are used as solvent to disperse the $\mathrm{Si}$ nanoparticles. The precursor of the silver nanoparticles (silver nitrate) is dissolved in the curing agent of diethylenetriamine (DETA) by forming the coordination bonds between silver and amine function groups. A further hardening process is applied to solidify the liquid epoxy resin solution by mixing the DER 331 resin and DETA solutions. The Si nanoparticles and silver ion species are incorporated into the thermosetting epoxy polymer network. By calcination in argon atmosphere, silver nanoparticles are in situ formed. Both silver and $\mathrm{Si}$ nanoparticles are homogeneously embedded in to the in situ formed continuous carbon matrix.

The strategy addressed in the present study has a few particular advantages as compared to so far published work. Firstly, the formation of the super-small silver nanoparticles is possible because the silver precursor is dissolved in the epoxy resin monomer solution and integrated into the epoxy cross-linking network through strong coordination bonds. The in situ carbonization process of the thermosetting epoxy resin network has a rather limited melting process, which effectively inhibits the nucleation and growth of the silver nanoparticles. Secondly, the in situ formed silver nanoparticles are homogeneously embedded in the in situ formed carbon matrix and the agglomeration of the super-small silver nanoparticles is significantly inhibited. Thirdly, the $\mathrm{Ag} / \mathrm{C}$ nanohybrid structure helps to retain reasonable powder tap density, which is usually a big challenge for nanostructured materials. Fourthly, continuous carbon matrix is formed instead of the individual carbon shell, which has more capability to accommodate the volume change and absorb mechanical stress of $\mathrm{Si}^{56}$ Fifthly, the use of amine based curing agent generates nitrogen doped carbon matrix, 
which is good to improve the electron conductivity of the $\mathrm{Si} / \mathrm{Ag} / \mathrm{C}$ nanohybrid, leading to enhanced electrochemical performance. Sixthly, the use of epoxy resin monomer as solvent circumvents the costly, tedious, and environmentally unfriendly post-processing procedure of conventional solvents.

\section{Results and Discussion}

The curing degree of the epoxy polymer is evaluated based on the Soxhlet extraction method using acetone as solvent. After extraction, the mass loss values of the Si/DER331 and $\mathrm{Si} / \mathrm{AgNO}_{3} / \mathrm{DER} 331$ composites are about $7.9 \%$ and $2.2 \%$ respectively. The results indicate that the epoxy monomers are almost fully polymerized. Highly cross-linked thermosetting epoxy/silver composites are successfully synthesized. 


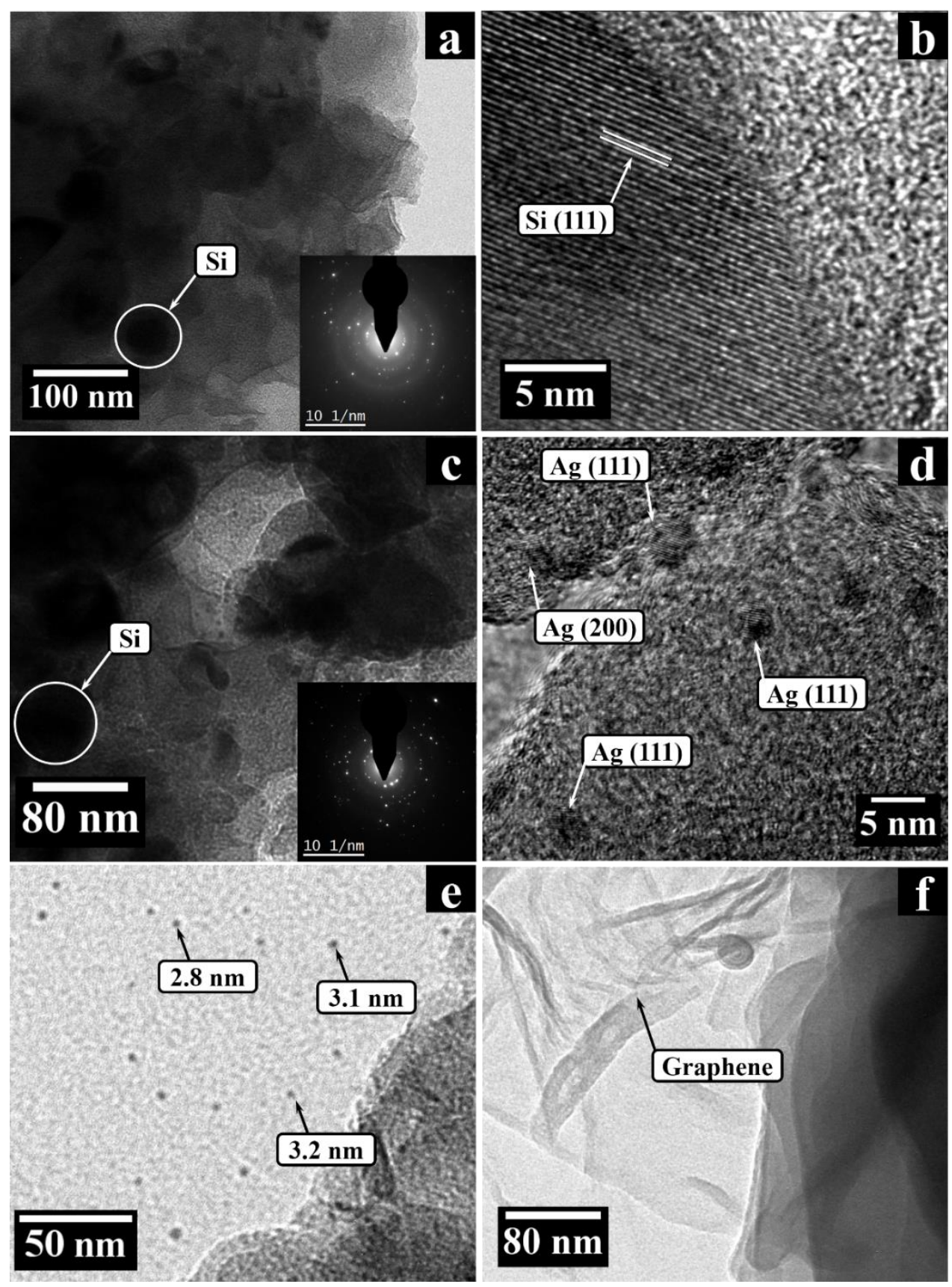

Figure 1. TEM images (a, c), SAED patterns (insets of image a and c), and HRTEM image (b, d) of the $\mathrm{Si} / \mathrm{C}(\mathrm{a}, \mathrm{b})$ and $\mathrm{Si} / \mathrm{Ag} / \mathrm{C}$ nanohybrids $(\mathrm{c}, \mathrm{d})$. The silver nanoparticles are embedded in the carbon matrix (e) and the local graphene structure is observed in the $\mathrm{Si} / \mathrm{Ag} / \mathrm{C}$ nanohybrids (f).

The TEM, HRTEM images and SAED patterns of the Si/C nanohybrids are shown in Figure 1a and Figure 1b. As shown in Figure 1a, the Si nanoparticles are well embedded in the carbon matrix and have a diameter of around $30 \mathrm{~nm}$. The SAED pattern in Figure 1a and HRTEM image 
(Figure $1 \mathrm{~b}$ ) confirm that the $\mathrm{Si}$ nanoparticles are well crystallized. Compared to the bare $\mathrm{Si} / \mathrm{C}$ sample, the $\mathrm{Si} / \mathrm{Ag} / \mathrm{C}$ nanohybrid shows a similar structure feature (Figure 1c), where $\mathrm{Si}$ and silver nanoparticles are embedded in carbon matrix. The HRTEM image in Figure 1d indicates that the in situ formed silver nanoparticles are of good crystallinity with a size of around $3 \mathrm{~nm}$. Figure 1e displays the structure of the in situ formed silver nanoparticles. The average size of the silver nanoparticles is estimated to be $2.9 \mathrm{~nm} \pm 0.5 \mathrm{~nm}$ based on the measurement of twelve silver nanoparticles. In addition, a local graphene structure is observed in the $\mathrm{Si} / \mathrm{Ag} / \mathrm{C}$ nanohybrid (Figure 1f). The formation of the graphene structure is due to a catalytic effect of the in situ formed silver nanoparticles during carbonization of the epoxy resin ${ }^{57}$. Furthermore, the EDX images show that $\mathrm{Si}$ and silver species are homogeneously dispersed in the carbon matrix in both $\mathrm{Si} / \mathrm{C}$ and $\mathrm{Si} / \mathrm{Ag} / \mathrm{C}$ nanohybrids (Figure 2).

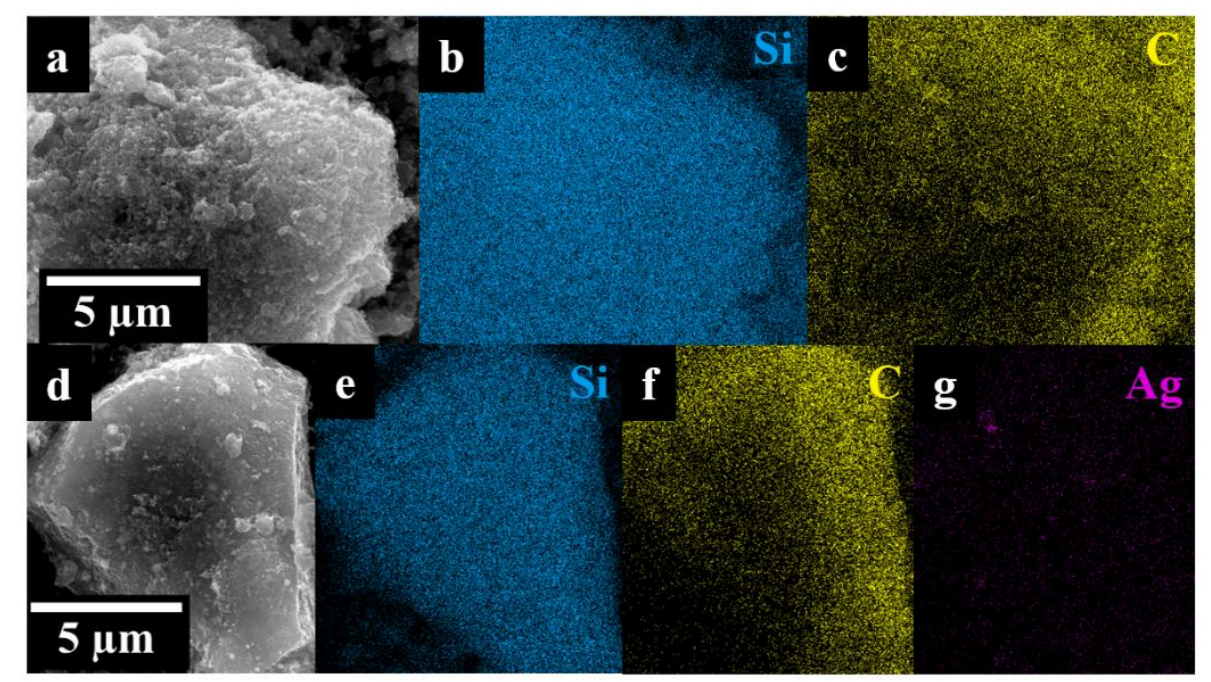

Figure 2. Elemental mapping of the Si/C (a: SEM image, b: element map of Si, c: element map of C ) and the Si/Ag/C nanohybrid (d: SEM image, e: element map of Si, f: element map of C, g: element map of $\mathrm{Ag}$ ).

Figure 3a shows the x-ray diffraction (XRD) patterns of the pristine and calcined nanohybrids. 
Before calcination, the Si/DER331 sample exhibits diffraction peaks located at $28.4^{\circ}, 47.3^{\circ}, 56.1^{\circ}$, $69.1^{\circ}, 76.4^{\circ}$, and $88.0^{\circ}$, which are assigned to the (111), (220), (311), (400), (331), and (422) crystal planes of the cubic Si phase (JCPDS NO.27-1402) ${ }^{58}$ Compared to the Si/DER331 sample, the $\mathrm{Si} / \mathrm{AgNO}_{3} / \mathrm{DER} 331$ sample shows weak diffraction peaks of silver metal apart from the peaks belonging to the Si. It indicates that small amount of silver ions are reduced to silver metal during sample preparation due to heat and/or light exposure. After calcination, the Si/C sample exhibits almost identical diffractions peaks to the pristine Si/DER331, which implies that the carbonization process does not modify the crystallinity of the Si nanoparticles. Regarding the $\mathrm{Si} / \mathrm{Ag} / \mathrm{C}$ nanohybrid, besides the peaks originated from the crystalline $\mathrm{Si}$, diffraction peaks with strong intensities belonging to the silver metal are observed. Specifically, the peaks located at $38.1^{\circ}, 44.4^{\circ}, 64.4^{\circ}$, $77.4^{\circ}$, and $81.5^{\circ}$ are ascribed to the (111), (200), (220), (311) and (222) crystalline planes of the cubic phase of silver (JCPDS card NO. 04-0783).$^{38}$ A broad peak at around $25^{\circ}$ is found with the calcined samples, which may be presented by the local graphitic carbon structure within the carbon matrix and/or the amorphous $\mathrm{SiO}_{2}$ formed on the surface of the $\mathrm{Si}$ nanoparticles. ${ }^{59}$ The broad peak located at around $18^{\circ}$ is observed only in the polymerized samples resulting from the local crystalline domains in the epoxy resin matrix. 

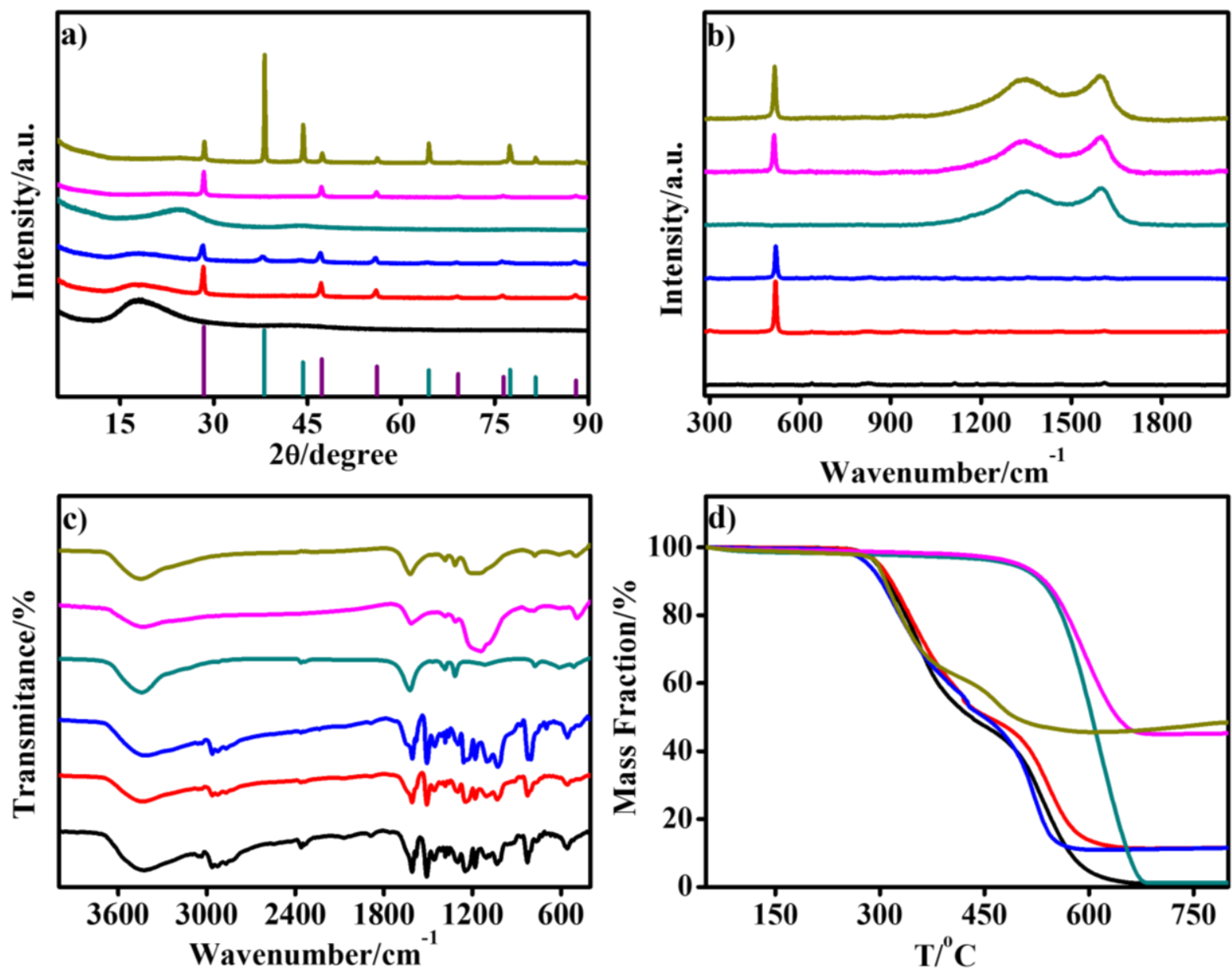

Figure 3. XRD (a), Raman (b), FTIR (c), and TGA (d) of the samples. Black: polymerized DER331; red: $\mathrm{Si} / \mathrm{DER} 331$; blue: $\mathrm{Si} / \mathrm{AgNO}_{3} / \mathrm{DER} 331$; dark cyan: bare carbon obtained by carbonization of the DER 331 epoxy resin; magenta: Si/C; dark yellow: Si/Ag/C. Purple/dark cyan lines in image 3a are the standard XRD patterns of Si and Ag.

The Raman spectra of the DER331, Si/DER331, Si/AgNO $3 / \mathrm{DER} 331$, bare carbon, Si/C, and $\mathrm{Si} / \mathrm{Ag} / \mathrm{C}$ are shown in Figure $3 \mathrm{~b}$. The peaks at around $515 \mathrm{~cm}^{-1}$ originate from the crystalline $\mathrm{Si}$ in the $\mathrm{Si} / \mathrm{DER} 331, \mathrm{Si} / \mathrm{AgNO}_{3} / \mathrm{DER} 331, \mathrm{Si} / \mathrm{C}$, and $\mathrm{Si} / \mathrm{Ag} / \mathrm{C}$ samples. After calcination, two additional peaks located at $1355 \mathrm{~cm}^{-1}$ and $1602 \mathrm{~cm}^{-1}$ appear in the bare carbon, $\mathrm{Si} / \mathrm{C}$ and $\mathrm{Si} / \mathrm{Ag} / \mathrm{C}$ samples. The two peaks correspond to the $A_{1 g}$ mode of the disordered carbon ( $D$ band) and $E_{2 g}$ mode of the graphitic carbon respectively ( $\mathrm{G}$ band). The integrated intensity ratios of the $\mathrm{D}$ band over the $\mathrm{G}$ 
band are $3.14(\mathrm{Si} / \mathrm{C})$ and $3.26(\mathrm{Si} / \mathrm{Ag} / \mathrm{C})$. It means that the disordered carbon is a major component within the carbon matrix. Furthermore, the increased disordered carbon content in the $\mathrm{Si} / \mathrm{Ag} / \mathrm{C}$ nanohybrid suggests that the addition of silver ions enhances the cross-linking degree of the epoxy polymers, leading to increased char yield from the aliphatic polymeric structural units.

Figure $3 c$ shows the FTIR spectra of the samples including DER331, Si/DER331, $\mathrm{Si} / \mathrm{AgNO}_{3} / \mathrm{DER} 331$, bare carbon, $\mathrm{Si} / \mathrm{C}$, and $\mathrm{Si} / \mathrm{Ag} / \mathrm{C}$. Concerning the samples before calcination, no peaks corresponding to the cyclic epoxy functional group is observed with the DER331, Si/DER331, and $\mathrm{Si} / \mathrm{AgNO}_{3} / \mathrm{DER} 331$ samples. The results indicate that the epoxy groups are completely cross-linked induced by the DETA curing agent. Regarding the calcined samples, a characteristic peak at $1620 \mathrm{~cm}^{-1}$ derived from the conjugation bond $\mathrm{C}=\mathrm{N}$ are observed in the bare carbon, $\mathrm{Si} / \mathrm{C}$, and $\mathrm{Si} / \mathrm{Ag} / \mathrm{C}$ samples. Particularly, the characteristic peaks at around $1100 \mathrm{~cm}^{-1}, 800$ $\mathrm{cm}^{-1}$ and $480 \mathrm{~cm}^{-1}$ in the $\mathrm{Si} / \mathrm{C}$ and $\mathrm{Si} / \mathrm{Ag} / \mathrm{C}$ samples can be assigned to $\mathrm{SiO}_{2}$ due to partial surface oxidation of the Si nanoparticles. ${ }^{60}$ The FTIR results indicate that nitrogen-doped carbon is obtained after carbonization due to the presence of the DETA curing agent. By comparing the FTIR profiles of the samples before and after calcination, it is found that the number of the peaks within the long wavelength range is significantly reduced after calcination. It reflects the fact that most of the organic moieties of the polymers are burned away. The broad peak located at $3425 \mathrm{~cm}^{-1}$ refers to the stretching vibration of the $\mathrm{N}-\mathrm{H}$ bond in amine. The existence of the $\mathrm{N}-\mathrm{H}$ bond in the polymerized samples indicates only part of the reactive hydrogen atoms is used for the cross-linking reaction. In addition, the existence of the broad peak after calcination indicates the nitrogen atoms are not fully removed during calcination. The overlapped peaks at $2870 \mathrm{~cm}^{-1}$ and $2960 \mathrm{~cm}^{-1}$ refer to the symmetric bending vibration and antisymmetric vibration of the $\mathrm{C}-\mathrm{H}$ bond in the methyl group 
of the pristine samples. The peak disappears after calcination, which indicates that the methyl group is completely burned off.

Figure $3 \mathrm{~d}$ shows the TG curves of the pristine and calcined samples measured in air atmosphere. The polymerized samples start to decompose from around $300{ }^{\circ} \mathrm{C}$ evidenced by the mass loss. Further mass loss at around $500{ }^{\circ} \mathrm{C}$ in the samples of DER331, Si/DER331, $\mathrm{Si} / \mathrm{AgNO}_{3} / \mathrm{DER} 331$, bare carbon and $\mathrm{Si} / \mathrm{C}$ originates from the burning of the carbon. Compared with the $\mathrm{Si} / \mathrm{C}$ and bare carbon samples, the early mass loss at around $300{ }^{\circ} \mathrm{C}$ in the $\mathrm{Si} / \mathrm{Ag} / \mathrm{C}$ nanohybrid is due to the presence of the graphene, which promotes the burning process by enhanced heat and gas transportation. ${ }^{57}$ The measured residual mass at $720^{\circ} \mathrm{C}$ of the $\mathrm{Si} / \mathrm{C}$ nanohybrid is about $42 \mathrm{wt} \%$, which corresponds to the Si content. For the Si/Ag/C nanohybrid, the remaining mass of $46 \mathrm{wt} \%$ at $650{ }^{\circ} \mathrm{C}$ is ascribed to the total amount of $\mathrm{Si}$ and $\mathrm{Ag}_{2} \mathrm{O}$. The silver content in $\mathrm{Si} / \mathrm{Ag} / \mathrm{C}$ nanohybrid obtained from the ICP-OES experiment is $2.59 \mathrm{wt} \%$. The exact content of $\mathrm{Si}$ in $\mathrm{Si} / \mathrm{Ag} / \mathrm{C}$ can be deduced from the results of TG and ICP-OES test. As a result, $43.3 \mathrm{wt} \%$ of $\mathrm{Si}$ are included in the $\mathrm{Si} / \mathrm{Ag} / \mathrm{C}$ nanohybrid.
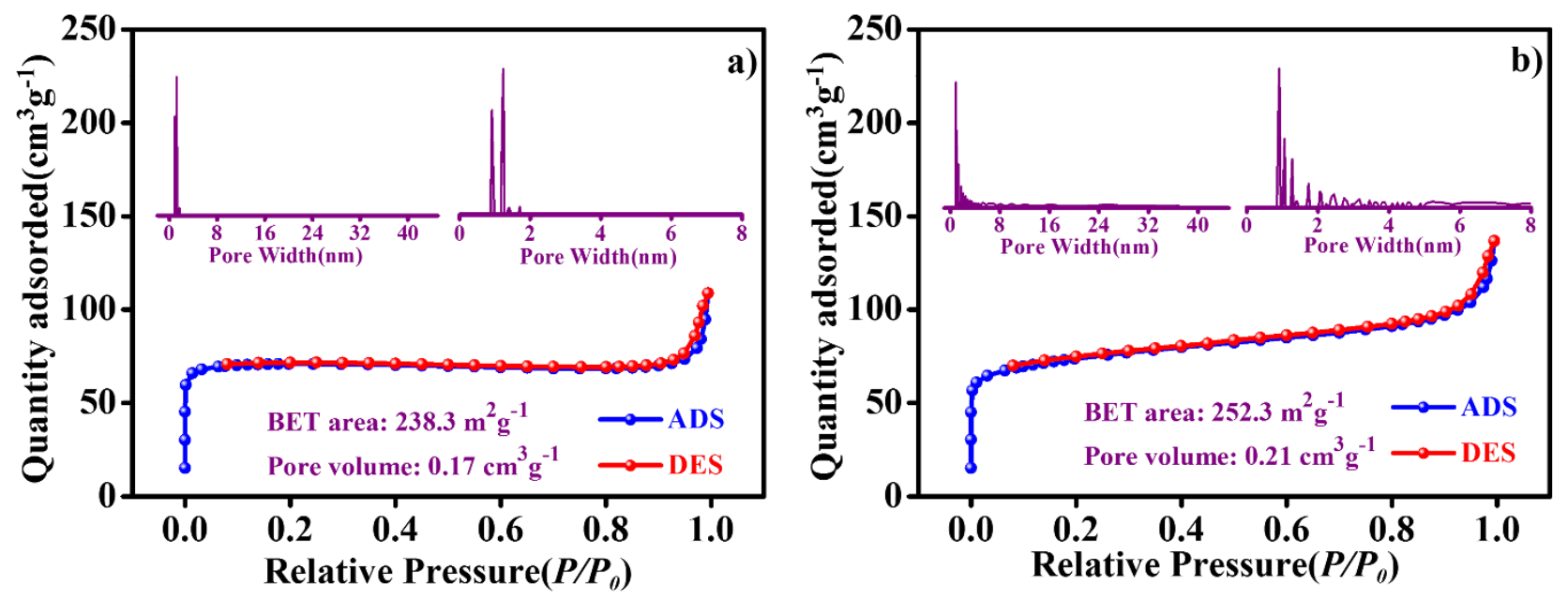

Figure 4. $\mathrm{N}_{2}$ adsorption/desorption isotherm curves and corresponding pore size distribution 
profiles (insets) of the $\mathrm{Si} / \mathrm{C}$ (a) and $\mathrm{Si} / \mathrm{Ag} / \mathrm{C}$ (b) nanohybrids. ADS: adsorption, DES: desorption.

Brunauer-Emmett-Teller (BET) gas sorption measurements are performed to investigate the porosity of the $\mathrm{Si} / \mathrm{C}$ and $\mathrm{Si} / \mathrm{Ag} / \mathrm{C}$ nanohybrids. $\mathrm{N}_{2}$ adsorption-desorption isotherms are shown in Figure 4, where corresponding porosity distribution profiles derived by density functional theory are depicted in the insets. As shown in the adsorption-desorption isotherms in Figure 4a and Figure $4 \mathrm{~b}$, the $\mathrm{Si} / \mathrm{C}$ and $\mathrm{Si} / \mathrm{Ag} / \mathrm{C}$ nanohybrids exhibit a mixed characteristics of micropores and mesopores. The rapid growth at low pressure can be assigned to the filling of the micropores, and the existence of the small hysteresis loop at high pressure results from the filling of the mesopores ${ }^{61}$. However, it can be found that the hysteresis loop is quite small, which suggests the presence of mesopores is very limited in the carbon matrix. The pore size distribution profiles of the $\mathrm{Si} / \mathrm{C}$ show that micropores exist with a quite uniform bimodal size of $0.9 \mathrm{~nm}$ and $1.2 \mathrm{~nm}$. Regarding the $\mathrm{Si} / \mathrm{Ag} / \mathrm{C}$ nanohybrid, the pore size distribution is slightly broader than that of the $\mathrm{Si} / \mathrm{C}$ sample. While micropores with the size in the range of from $0.8 \mathrm{~nm}$ to $1.8 \mathrm{~nm}$ are observed, small amount of mesopores are also exhibited in the profile. The relative broad size distribution of the pores is due to the presence of additional local graphene structure and the heterogeneous interface between the carbon matrix and silver nanoparticles. The BET specific surface area of the $\mathrm{Si} / \mathrm{C}$ and $\mathrm{Si} / \mathrm{Ag} / \mathrm{C}$ nanohybrids are measured to be $238.3 \mathrm{~m}^{2} \mathrm{~g}^{-1}$ and $252.3 \mathrm{~m}^{2} \mathrm{~g}^{-1}$ respectively. And the total pore volume of the $\mathrm{Si} / \mathrm{C}$ and $\mathrm{Si} / \mathrm{Ag} / \mathrm{C}$ are $0.17 \mathrm{~cm}^{3} \mathrm{~g}^{-1}$ and $0.21 \mathrm{~cm}^{3} \mathrm{~g}^{-1}$ respectively $\left(\mathrm{P} / \mathrm{P}_{0:}\right.$ 0.9942). The slightly increased specific surface area and pore volume of the $\mathrm{Si} / \mathrm{Ag} / \mathrm{C}$ nanohybrid are likely due to the formation of local graphene structure and the incorporation of super-small silver nanoparticles. 

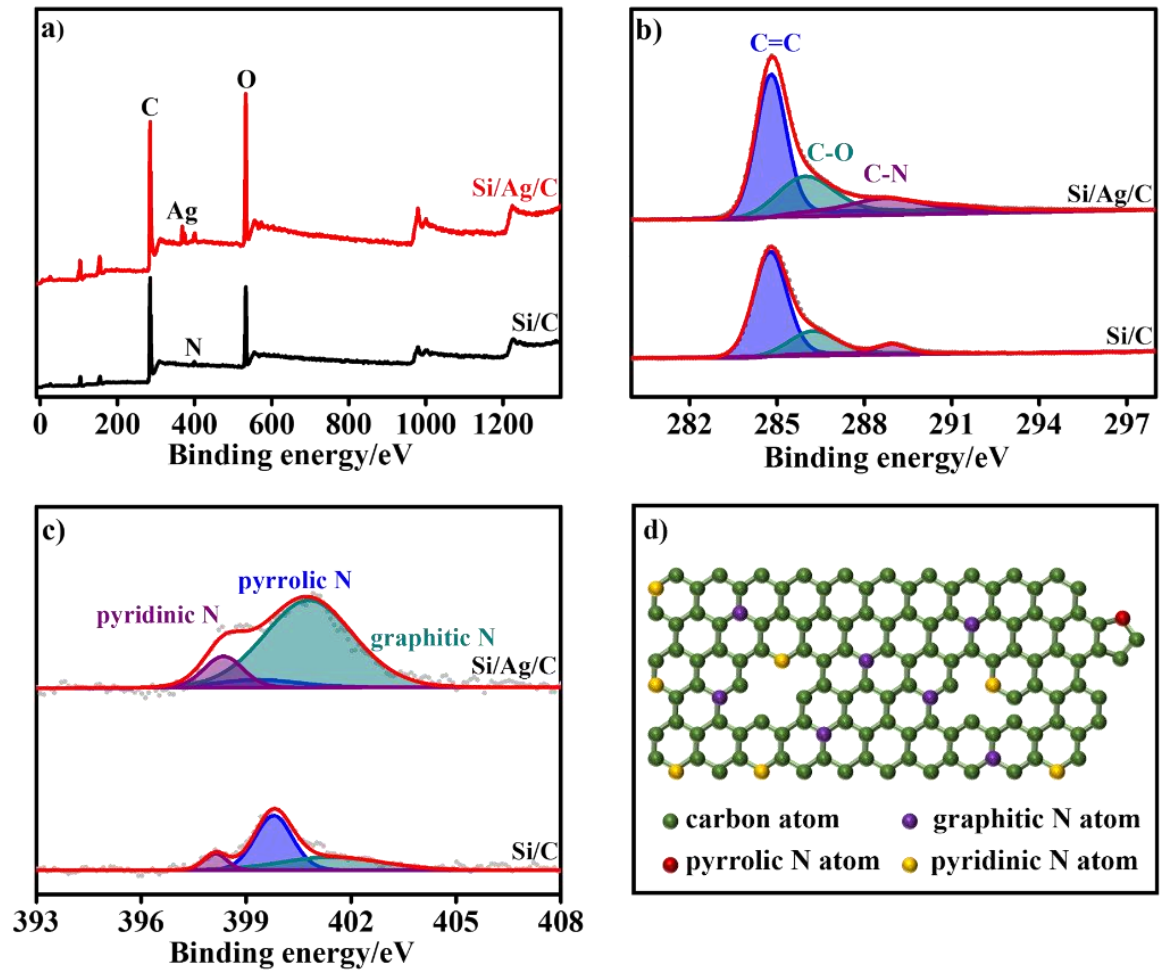

Figure 5. XPS spectra of the $\mathrm{Si} / \mathrm{C}$ and $\mathrm{Si} / \mathrm{Ag} / \mathrm{C}$ nanohybrids: survey spectrum of the $\mathrm{Si} / \mathrm{C}$ and $\mathrm{Si} / \mathrm{Ag} / \mathrm{C}$ (a), High resolution XPS spectra of the $\mathrm{C} 1 \mathrm{~s}$ in the $\mathrm{Si} / \mathrm{C}$ and $\mathrm{Si} / \mathrm{Ag} / \mathrm{C}(\mathrm{b})$, high resolution XPS spectra of the N1s in the $\mathrm{Si} / \mathrm{C}$ and $\mathrm{Si} / \mathrm{Ag} / \mathrm{C}$ (c), and schematic structure of nitrogen doped carbon (d). Grey point: experimental data, red line: fitted curves.

The x-ray photoelectron spectra (XPS) of the $\mathrm{Si} / \mathrm{C}$ and $\mathrm{Si} / \mathrm{Ag} / \mathrm{C}$ samples suggest that Nitrogen doping happens in the carbon matrix because the amine based curing agent (DETA) is used (Figure 5). The characteristic peaks at $285 \mathrm{eV}, 400 \mathrm{eV}$ and $532 \mathrm{eV}$ in Figure 5a correspond to the C1s, N1s and $\mathrm{O} 1 \mathrm{~s}$, respectively ${ }^{62}$. As exhibited by Figure $5 \mathrm{~b}$, the $\mathrm{C} 1 \mathrm{~s}$ spectrum of the $\mathrm{Si} / \mathrm{C}$ and $\mathrm{Si} / \mathrm{Ag} / \mathrm{C}$ nanohybrids can be deconvoluted into three individual peaks. The sharp peak at $284.5 \mathrm{eV}$ corresponds to the $\mathrm{sp}^{2}$ carbon atoms, which indicates the presence of graphitic carbon. The characteristic peak at $286.2 \mathrm{eV}$ refers to the $\mathrm{C}-\mathrm{O}$ bonding. And the peak at $289 \mathrm{eV}$ is ascribed to the $\mathrm{C}-\mathrm{N}$ bond, which originates from the incorporation of the diethylenetriamine curing agent in the 
epoxy polymer network. ${ }^{63}$ It is found that the intensity of the peak at $286.2 \mathrm{eV}$ is much weaker than that of the peak at $284.5 \mathrm{eV}$. It indicates the existence of only small amount of C-O bonding within the carbon matrix. ${ }^{64}$ Furthermore, compared with the Si/C sample, the full width of half-maximum (FWHM) of the peak at $289 \mathrm{eV}$ in the $\mathrm{Si} / \mathrm{Ag} / \mathrm{C}$ nanohybrid is slightly increased. It means that the incorporation of silver facilitates the formation of the C-N bond. The detailed XPS spectra of N1s further proves the existence of the nitrogen species in the samples (Figure 5c). The characteristic peaks at $398.2 \mathrm{eV}, 399.5 \mathrm{eV}$ and $401.2 \mathrm{eV}$ confirm the existence of pyridinic $\mathrm{N}$, pyrrolic $\mathrm{N}$ and graphitic $\mathrm{N}$ (Figure 5d) in the carbon matrix of the $\mathrm{Si} / \mathrm{C}$ and $\mathrm{Si} / \mathrm{Ag} / \mathrm{C}$ nanohybrids. It seems that the relative compositions of the graphitic $\mathrm{N}$ and pyrrolic $\mathrm{N}$ are increased significantly compared to the pyridine $\mathrm{N}$ in the $\mathrm{Si} / \mathrm{Ag} / \mathrm{C}$ nanohybrid.

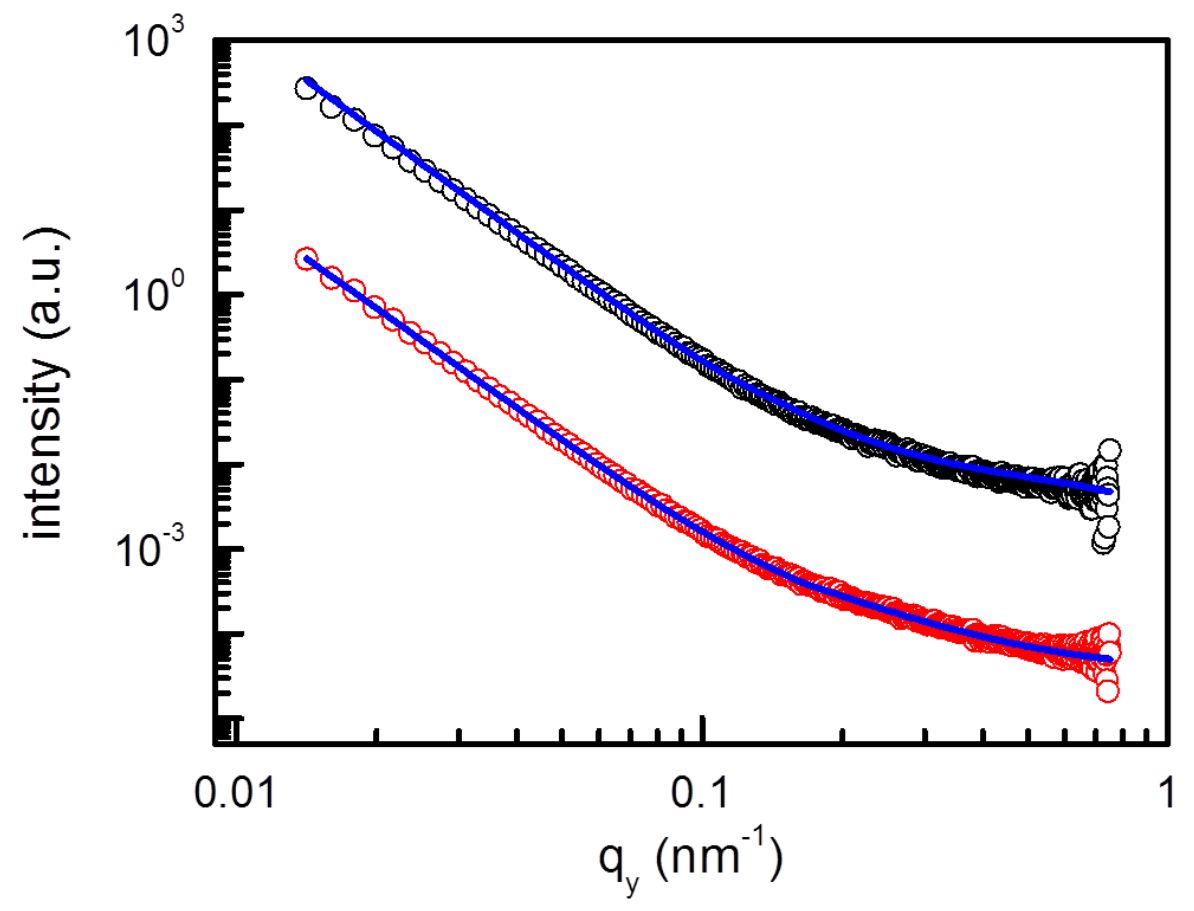

Figure 6. Experimental (open circle) and fitting (solid lines) SAXS of the Si/C (black circle) and $\mathrm{Si} / \mathrm{Ag} / \mathrm{C}$ (red circle) nanohybrids.

Besides the imaging analysis in local areas, the average statistic structure information on the 
$\mathrm{Si} / \mathrm{C}$ and $\mathrm{Si} / \mathrm{Ag} / \mathrm{C}$ nanohybrids is investigated by SAXS. According to Figure 6, similar scattering behaviors are observed in the SAXS data, in which both curves are displayed with no distinguished peaks. This reveals random distribution of nanoparticles. Being confirmed by TEM, spherical Si and Ag nanoparticles are dispersed randomly inside carbon matrix. Therefore, the SAXS cuts are modeled with only sphere form factor with a Gaussian distribution function. No structure factor is applied to the fitting. According to the fitting, Si particles with diameter of $42 \pm 4 \mathrm{~nm}$ are obtained in the Ag-free sample. With incorporation of silver, the size of Si particles stays as a constant, and 3 $\pm 1 \mathrm{~nm}$ of silver nanoparticles are present in the nanohybrids.
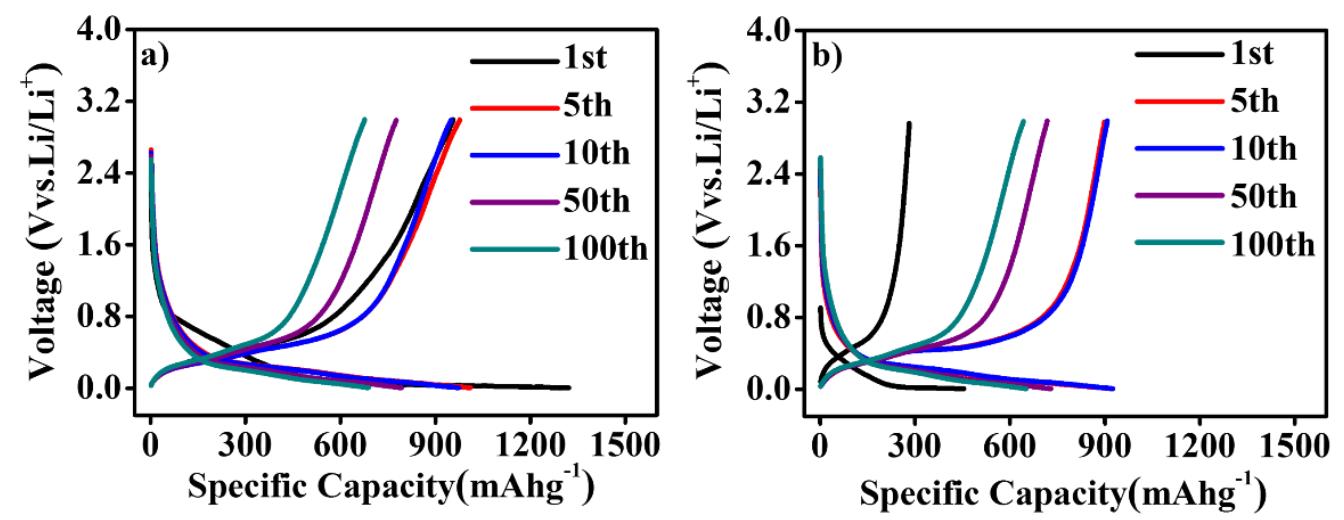

Figure 7. Discharge/charge curves $\left(0.2 \mathrm{C}, 1 \mathrm{C}=1000 \mathrm{mAg}^{-1}\right)$ of the $\mathrm{Si} / \mathrm{C}$ (a) and $\mathrm{Si} / \mathrm{Ag} / \mathrm{C}$ nanohybrids (b).

The discharge and charge curves of the $\mathrm{Si} / \mathrm{C}$ and $\mathrm{Si} / \mathrm{Ag} / \mathrm{C}$ nanohybrids are shown in Figure 7 for a current density of $200 \mathrm{mAg}^{-1}$ between $0.005 \mathrm{~V}$ and $3 \mathrm{~V}$ (vs. $\mathrm{Li}^{-} \mathrm{Li}^{+}$). It is reported that the crystalline Si possesses a well-defined discharging plateau at about $0.1 \mathrm{~V}$ and a charging potential at about $0.45 \mathrm{~V}$ during the lithiation/delithiation processes. ${ }^{65}$ And the pyrolyzed carbon material obtained from the polymer resin often exhibits unobvious plateau during the discharge/charge processes. $^{52}$ Therefore, the $\mathrm{Si} / \mathrm{C}$ and $\mathrm{Si} / \mathrm{Ag} / \mathrm{C}$ nanohybrids synthesized in this work exhibit a mixed behavior of $\mathrm{Si}$ and pyrolytic carbon. Compared with the discharge/charge curves of the $\mathrm{Si} / \mathrm{C}$ 
composite, no additional characteristic plateau can be found in the Si/Ag/C nanohybrids, which suggests that the lithiation of silver is rather limited. Correspondingly, it is reasonable to conclude that the capacity mainly comes from the $\mathrm{Si}$ and carbon matrix. ${ }^{66}$ Furthermore, the discharging plateau at around $0.6 \mathrm{~V}$ in the first cycle is assigned to the formation of the SEI films. ${ }^{67}$ It is also found that the $\mathrm{Si} / \mathrm{Ag} / \mathrm{C}$ composite undergoes an activation process in the first few cycles, which may result from the gradual infiltration of the electrolyte. ${ }^{68}$ The $5^{\text {th }}$ and $10^{\text {th }}$ charge/discharge curves of the $\mathrm{Si} / \mathrm{C}$ and $\mathrm{Si} / \mathrm{Ag} / \mathrm{C}$ nanohybrids are almost identical, which indicates that the electrodes possess good cyclic stability until at least the $10^{\text {th }}$ cycle. Regarding the discharge/charge profiles of the $50^{\text {th }}$ and $100^{\text {th }}$ cycle of the $\mathrm{Si} / \mathrm{C}$ and $\mathrm{Si} / \mathrm{Ag} / \mathrm{C}$ electrodes, the patterns are still quite similar to the curves of the $10^{\text {th }}$ cycle. It means that the fundamental electrochemical process is stable even though some capacities are lost with increased cycles.
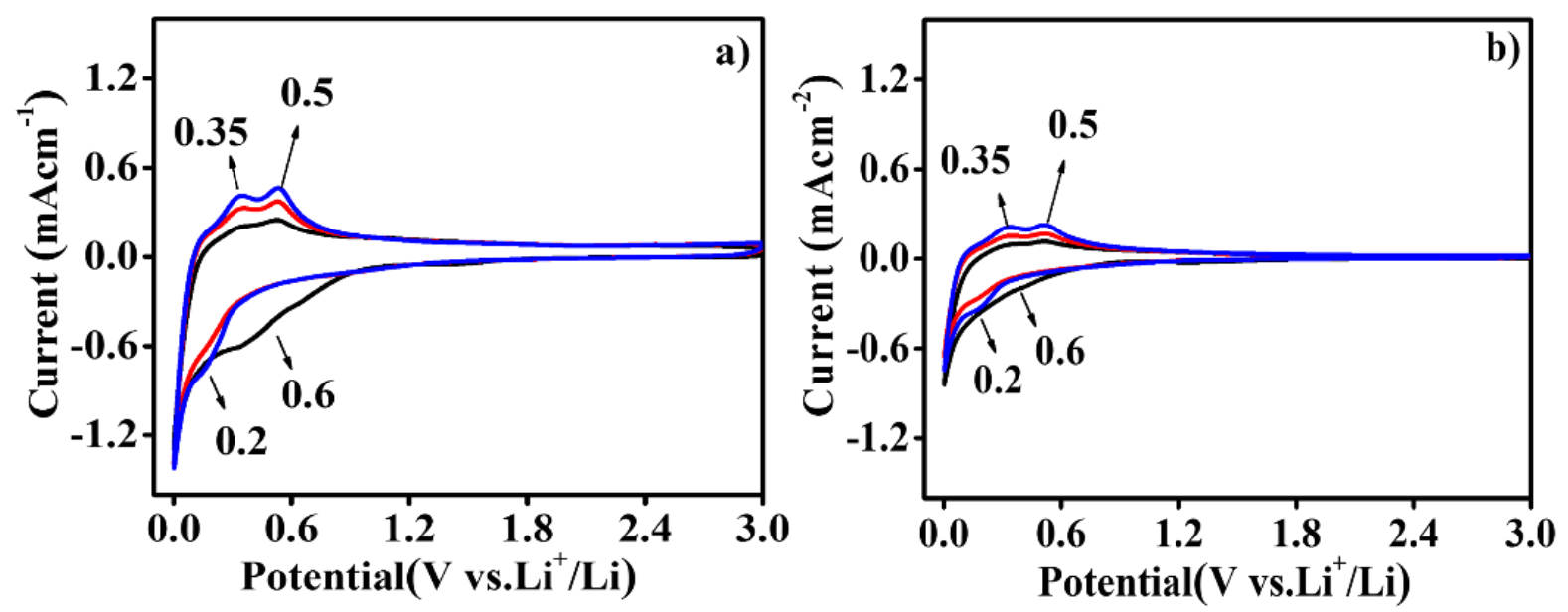

Figure 8. Cyclic voltammetry $(\mathrm{CV})$ of the $\mathrm{Si} / \mathrm{C}$ (a) and the $\mathrm{Si} / \mathrm{Ag} / \mathrm{C}$ (b) electrodes with different cycles. (black: $1^{\text {st }}$, red: $2^{\text {nd }}$, and blue: $3^{\text {rd }}$ ).

Figure 8 shows the cyclic voltammetry $(\mathrm{CV})$ of the $\mathrm{Si} / \mathrm{C}$ and the $\mathrm{Si} / \mathrm{Ag} / \mathrm{C}$ electrodes. The broad cathodic peak at around $0.6 \mathrm{~V}$ is observed in the first cycle and then disappears in the subsequent cycles (Figure 8a, 8b). It indicates the formation of a SEI film on the surface of the active material, 
which is in good agreement with the discharge/charge curves ${ }^{67}$. Considering that the characteristic peak around $0.6 \mathrm{~V}$ mainly appears in the carbon based electrode material, it suggests that the $\mathrm{Si}$ nanoparticles are well embedded in the carbon matrix. The anodic peaks at $0.35 \mathrm{~V}$ and $0.5 \mathrm{~V}$ are associated with the successive transitions from highly lithiated $\mathrm{Si}$ to less-lithiated and further non-lithiated $\mathrm{Si}^{69-70} \mathrm{~A}$ new peak is observed at $0.2 \mathrm{~V}$ as opposed to the first discharge process, resulting from the reaction of lithium with $\mathrm{Si}$ to form amorphous $\mathrm{Li}_{\mathrm{x}} \mathrm{Si}$, which needs a possible activation process during the insertion/extraction. ${ }^{51,71-73}$ Peaks related to the reaction between Ag and $\mathrm{Li}$ are not detected, which indicates that the lithiation of silver is quite limited. ${ }^{65}$

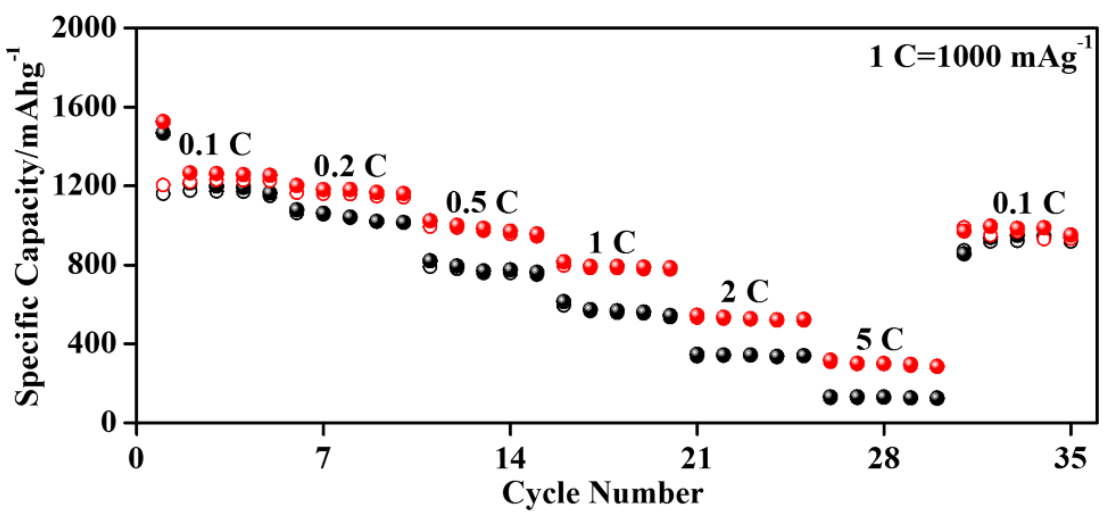

Figure 9. Rate performance of the $\mathrm{Si} / \mathrm{C}$ and $\mathrm{Si} / \mathrm{Ag} / \mathrm{C}$ nanohybrids. Black: $\mathrm{Si} / \mathrm{C}$, red: $\mathrm{Si} / \mathrm{Ag} / \mathrm{C}$, sphere: discharge capacity, open circle: charge capacity.

The rate performance of the $\mathrm{Si} / \mathrm{C}$ and $\mathrm{Si} / \mathrm{Ag} / \mathrm{C}$ nanohybrids at different current densities is shown in Figure 9. And the corresponding average discharge capacities of the $\mathrm{Si} / \mathrm{C}$ and $\mathrm{Si} / \mathrm{Ag} / \mathrm{C}$ nanohybrid electrodes at different current densities are listed in Table 3.

Table 3. Average discharge capacities of the $\mathrm{Si} / \mathrm{C}$ and $\mathrm{Si} / \mathrm{Ag} / \mathrm{C}$ summarized from Figure 9.

\begin{tabular}{cccccccc}
\hline & \multicolumn{6}{c}{ Average discharge capacities at different current densities/mAhg } \\
\cline { 2 - 8 } Sample & 0.1 C & $\mathbf{0 . 2} \mathbf{C}$ & $\mathbf{0 . 5 ~ C}$ & 1 C & 2 C & 5 C & 0.1 C \\
\hline Si/C & 1247 & 1043 & 784 & 572 & 342 & 128 & 926 \\
$\mathrm{Si} / \mathrm{Ag} / \mathrm{C}$ & 1313 & 1179 & 988 & 795 & 530 & 299 & 978 \\
\hline
\end{tabular}


Note: $1 \mathrm{C}=1000 \mathrm{mAg}^{-1}$.

Compared to $\mathrm{Si} / \mathrm{C}$, the $\mathrm{Si} / \mathrm{Ag} / \mathrm{C}$ nanohybrid exhibits higher capacity at each individual current density, especially at the high current densities. For example, the Si/C electrode shows average discharge capacities of $784 \mathrm{mAhg}^{-1}, 572 \mathrm{mAhg}^{-1}, 342 \mathrm{mAhg}^{-1}$ and $128 \mathrm{mAhg}^{-1}$ at $0.5 \mathrm{C}, 1 \mathrm{C}, 2 \mathrm{C}$ and $5 \mathrm{C}$ respectively. However, the $\mathrm{Si} / \mathrm{Ag} / \mathrm{C}$ nanohybrid electrode exhibits average discharge capacities of $988 \mathrm{mAhg}^{-1}, 795 \mathrm{mAhg}^{-1}, 530 \mathrm{mAhg}^{-1}$, and $299 \mathrm{mAhg}^{-1}$ at the same current densities (Table 3). When the current density is changed back from $5 \mathrm{C}$ to $0.1 \mathrm{C}$, the average discharge capacities of the $\mathrm{Si} / \mathrm{C}$ and $\mathrm{Si} / \mathrm{Ag} / \mathrm{C}$ electrodes are restored to $926 \mathrm{mAhg}^{-1}$ and $978 \mathrm{mAhg}^{-1}$ respectively. The results suggest that the $\mathrm{Si} / \mathrm{Ag} / \mathrm{C}$ possesses good cyclic stability and rate performance. The significantly improved rate performance of the $\mathrm{Si} / \mathrm{Ag} / \mathrm{C}$ composite mainly benefit from the uniform dispersion of super-small silver nanoparticles in the carbon matrix. The incorporation of the silver nanoparticles leads to a significant increase of the electron transportation path within the nanohybrid. ${ }^{74}$
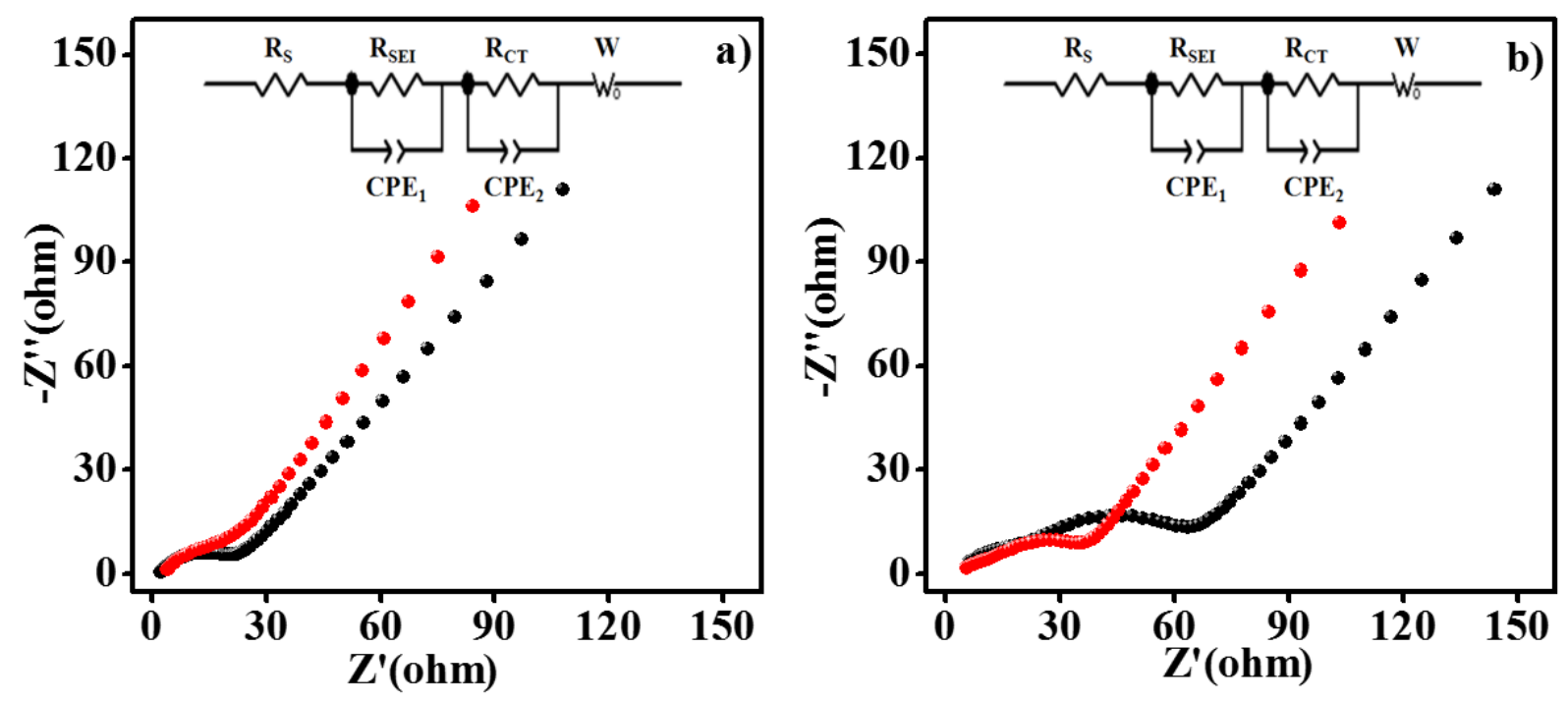

Figure 10. Electrochemical impedance spectra of the $\mathrm{Si} / \mathrm{C}$ (black) and the $\mathrm{Si} / \mathrm{Ag} / \mathrm{C}$ (red) nanohybrid electrodes after 3 cycles (a) and after 100 cycles (b).

Table 5. Representative fitting data of EIS spectroscopy of the $\mathrm{Si} / \mathrm{C}$ and $\mathrm{Si} / \mathrm{Ag} / \mathrm{C}$ nanohybrids. 


\begin{tabular}{ccc}
\hline R / SAMPLE & Si/C & Si/Ag/C \\
\hline$\left(\mathrm{R}_{\mathrm{S}}+\mathrm{R}_{\mathrm{SEI}}+\mathrm{R}_{\mathrm{CT}}\right)_{3}(\Omega)$ & 25.4 & 20.3 \\
$\left(\mathrm{R}_{\mathrm{S}}+\mathrm{R}_{\mathrm{SEI}}+\mathrm{R}_{\mathrm{CT}}\right)_{100}(\Omega)$ & 65.6 & 33.2 \\
\hline
\end{tabular}

Figure 10 shows the electrochemical impedance spectra of the $\mathrm{Si} / \mathrm{C}$ and $\mathrm{Si} / \mathrm{Ag} / \mathrm{C}$ nanohybrids after 3 cycles and 100 cycles respectively. The insets in the spectrum refer to the equivalent circuit model used to fit the EIS experimental profiles. ${ }^{75}$ Although the slopes of the straight lines are very similar, the dimensions of the semicircles are different with the incorporation of the silver nanoparticles. Compared to the impedance spectrum of the $\mathrm{Si} / \mathrm{C}$ and $\mathrm{Si} / \mathrm{Ag} / \mathrm{C}$ after three cycles, the semicircle dimensions of the $\mathrm{Si} / \mathrm{C}$ and $\mathrm{Si} / \mathrm{Ag} / \mathrm{C}$ after 100 cycles are obviously increased. It suggests that the charge transfer resistance of electrodes is increased along with increased cycles, which is due to the partial degradation of the electrode structure. ${ }^{75}$ In addition, the semicircle dimensions of the $\mathrm{Si} / \mathrm{Ag} / \mathrm{C}$ nanohybrids after three and one hundred cycles are significantly narrower compared to those of the $\mathrm{Si} / \mathrm{C}$ electrodes with the same cycle. This finding is also supported by the fitted parameters listed in Table 5. The decreased resistance values in the $\mathrm{Si} / \mathrm{Ag} / \mathrm{C}$ nanohybrids originate from the homogeneous incorporation of the super-small silver nanoparticles in the carbon matrix. The silver metal has superior electron conductivity than the carbon matrix. Additionally, the super-small structure feature of the silver nanoparticles is particularly helpful to improve the overall electron transportation property of the nanohybrids. The silver nanoparticles provide tremendous amounts of additional charge carrier transport routes with exceptional electron conductivity in the carbon matrix, which effectively increases the charge carrier transfer resistance. The increase of the charge carrier transportation brought by the silver nanoparticles is calculated as following:

Radius of original particle: $\mathrm{R}_{1}$ 
The particle with the radius of $R_{1}$ is divided into $N$ particles with the radius of $R_{2}$.

Number of the new particles: $N=\left(\frac{R_{1}}{R_{2}}\right)^{3}$

Total surface area incease: $\frac{A 2}{A 1}=N * \frac{4 \pi \mathrm{R}_{2}{ }^{2}}{4 \pi \mathrm{R}_{1}{ }^{2}}=\left(\frac{\mathrm{R}_{1}}{\mathrm{R}_{2}}\right)^{3} * \frac{4 \pi \mathrm{R}_{2}{ }^{2}}{4 \pi \mathrm{R}_{1}{ }^{2}}=\frac{\mathrm{R}_{1}}{\mathrm{R}_{2}}$

Total charge carrier transportation length incease: $\frac{L 2}{L 1}=\mathrm{N} * \frac{2 \mathrm{R}_{2}}{2 \mathrm{R}_{1}}=\left(\frac{\mathrm{R}_{1}}{\mathrm{R}_{2}}\right)^{3} * \frac{\mathrm{R}_{2}}{\mathrm{R}_{1}}=\left(\frac{R 1}{R 2}\right)^{2}$

It can be found that the super-small silver nanoparticles provide extra transport routs by a factor of $\left(\mathrm{R}_{1} / \mathrm{R}_{2}\right)^{2}$. Furthermore, it is interesting to observe that the charge carrier transportation length enhancement is even more pronounced than that of the surface area, which is only proportional to the order of $\mathrm{R}_{1} / \mathrm{R}_{2}$. Considering that there is $2.59 \mathrm{wt} \%$ of silver with the average diameter of $2.9 \mathrm{~nm}$ in the $\mathrm{Si} / \mathrm{Ag} / \mathrm{C}$ nanohybrid electrode with the mass loading density of 1.21 $\mathrm{mgcm}^{-2}$, the total charge carrier transport length provided by the silver nanoparticles on the copper current collector is derived as following:

$1.21 \times 10^{-3} \mathrm{gcm}^{-2} \times 2.59 \% \div\left(10.49 \mathrm{gcm}^{-3}\right) \div\left(\frac{4}{3} \times \pi \times\left(1.45 \times 10^{-7} \mathrm{~cm}\right)^{3}\right) \times 2.9 \times 10^{-9} \mathrm{~m}=6.7 \times$ $10^{5} \mathrm{mcm}^{-2}$

It can be found that the silver nanoparticles bring a total length of $6.7 \times 10^{5} \mathrm{~m}$ for electron transportation on each $1 \mathrm{~cm}^{-2}$ electrode. It is reasonable to ascribe the significantly improved rate performance of the $\mathrm{Si} / \mathrm{Ag} / \mathrm{C}$ nanohybrid anode to the existence of the super-small silver nanoparticles.

Besides the evaluation of the charge carrier transportation length provided by the super-small silver nanoparticles, the mechanism of charge carrier transportation of the $\mathrm{Si} / \mathrm{Ag} / \mathrm{C}$ nanohybrids is also investigated. The temperature dependent electron conductivity of the $\mathrm{Si} / \mathrm{Ag} / \mathrm{C}$ nanohybrids with the silver mass composition of $0,2.591 \%, 3.994 \%$, and $4.552 \%$ are measured. The carbon matrix mainly consists of graphite crystalline and amorphous carbon as confirmed by Raman and TEM 
measurements. Graphite is a semimetal with delocalized carriers, whereas amorphous carbon is a disordered system where transportation relies on hopping between discrete energy levels. The high conductivity and the ohmic character displayed in Figure 11a and Figure S1 in the supporting information implies that the dominant transportation mechanism in the $\mathrm{Si} / \mathrm{Ag} / \mathrm{C}$ nanohybrid is band-like rather than hopping between desecrate sites. The resistivity decreases monotonically with the increasing temperature, indicative of a semiconductor-behavior. We hereby model the $\mathrm{Si} / \mathrm{Ag} / \mathrm{C}$ system as a semiconductor system where the transportation is determined by the density and the mobility of the charge carriers. The charge carrier density depends on the thermal population of the band edge of the graphite whereas the carrier mobility counts both the carrier scattering within the graphite flakes and their transportation between the flakes through the amorphous carbon regions. Assuming identical mobility of electrons and holes, the resistivity reads ${ }^{76}$

$\rho=(q \mu n)^{-1}$

where $q$ is the elementary charge, $n$ is the density of carriers including electrons and holes, and $\mu$ is the mobility of the carriers.

We note that the carrier mobility, $\mu$, has been assumed to take the form of

$\mu=\mu_{i}^{-1}+A_{0} T$

in modeling the temperature dependent conductivity of graphite thin flakes, ${ }^{76}$ where $\mu_{i}{ }^{-1}$ is the contribution from static scattering centers and $A_{0}$ is a constant corresponding to the electron-phonon scattering in graphite. In this hybrid $\mathrm{Si} / \mathrm{Ag} / \mathrm{C}$ system, $A_{0}$ can be seen as the first-order temperature coefficient with the scattering and the thermal activation incorporated.

For simplicity, holes and electrons are treated equally, which yields a carrier density, $n$, as 
$n=2 \int_{0}^{+\infty} f(E) N(E) \mathrm{d} E$

where $f(E)$ is the Fermi-Dirac distribution function, and $N(E)$ is the density of states (DOS) for 2D electrons in the graphite. As the thermally excited carriers populate only the conduction band minimum and valance band maximum, the simple two-band (STB) model with parabolic band edge can well describe the energy spectrum, ${ }^{77}$ which reads

$E(k)=k^{2} / 2 m^{*}$

where $m^{*}$ is the band effective mass of electrons and holes and $k$ is the wave vector in vicinity of the band edge. By taking the two-dimensional DOS and substituting Eqs. (2, 3) into Eq. (1), we get $\rho(T)=(A+B T) \cdot\left[T \ln \left(1+e^{E_{F} / k_{B} T}\right)\right]^{-1}$

where $A$ and $B$ are fitting parameters with the coefficients in Eq. (2) and the integral constant of Eq. (3) absorbed, $E_{F}$ is the Fermi level, and $k_{B}$ is the Boltzmann constant. 

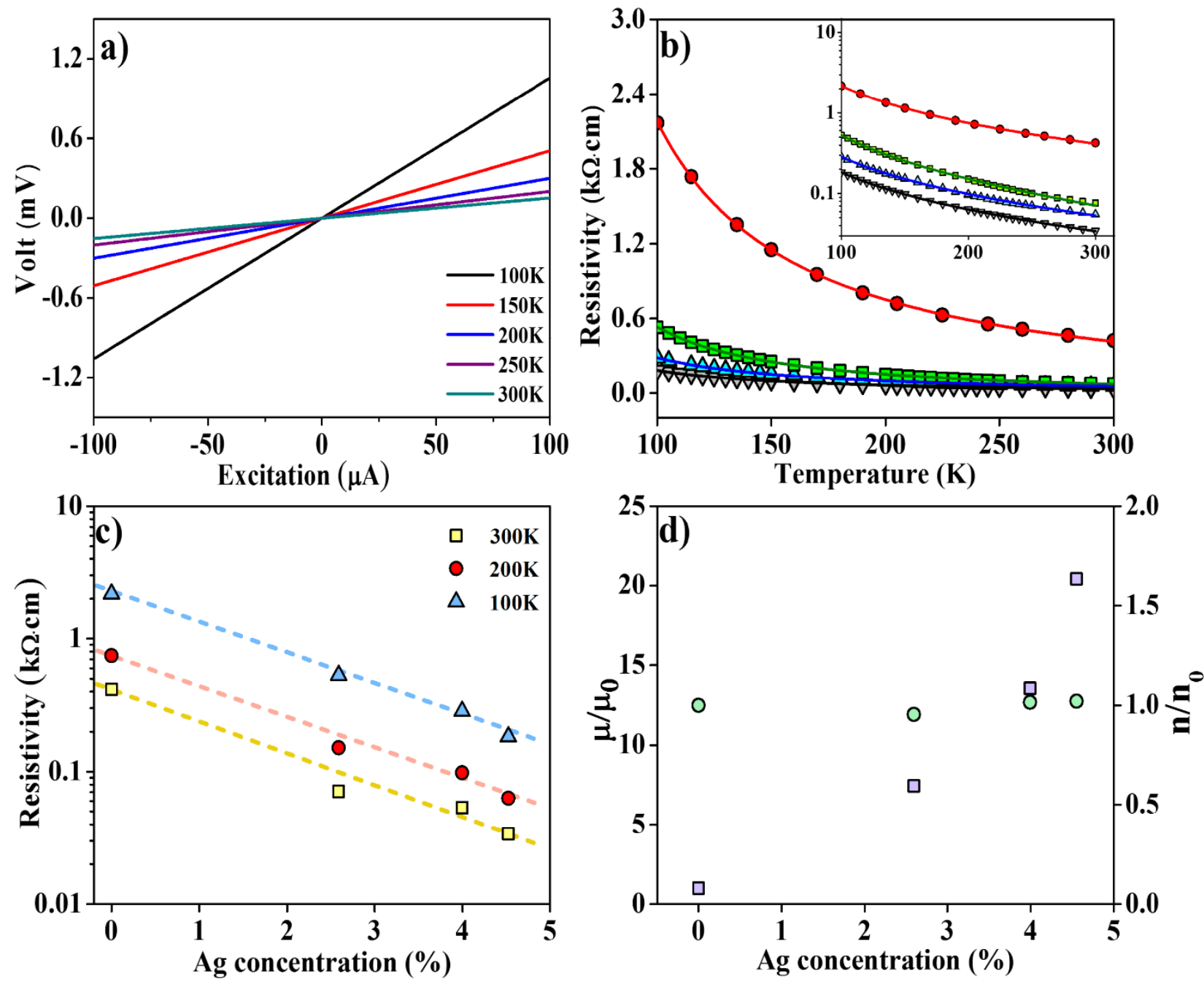

Figure 11. Typical I-V curves of the $\mathrm{Si} / \mathrm{Ag} / \mathrm{C}$ nanohybrid with the silver composition of $4.552 \%$ at different temperatures (a), temperature dependent resistivity profiles of the $\mathrm{Si} / \mathrm{Ag} / \mathrm{C}$ nanohybrids (b) (silver content: $0 \%$ (red), $2.591 \%$ (green), $3.994 \%$ (blue), and $4.552 \%$ (gray), symbols: experimental data, lines: fitting results), resistivity-silver content correlation of the $\mathrm{Si} / \mathrm{Ag} / \mathrm{C}$ nanohybrids with varied silver contents at different temperatures (c, symbols: experimental data, dash lines: guide to eyes), mobility (purple square) and charge carrier density (green circle) of the $\mathrm{Si} / \mathrm{Ag} / \mathrm{C}$ nanohybrids with different silver compositions.

In the $\mathrm{Si} / \mathrm{Ag} / \mathrm{C}$ system, the low concentration of $\mathrm{Ag}$ particles unlikely form percolating networks; the temperature dependence of the $\rho-T$ correlation for all the Ag concentrations exhibited 
in Figure $11 \mathrm{~b}$ confirms that the $\mathrm{Si} / \mathrm{Ag} / \mathrm{C}$ system is semiconductor-like, indicating that the charge transportation is mainly in the carbon matrix. Therefore Eq. (5) still applies. Using Eq. (5), the temperature dependence of the resistivity for the $\mathrm{Si} / \mathrm{Ag} / \mathrm{C}$ system with different concentrations of Ag nanoparticles can be well fitted, as show in Figure $11 \mathrm{~b}$. The fitting parameters, $A, B$ and the Fermi level $E_{F}$ are listed in Table 6. With increasing concentration of $\mathrm{Ag}$ nanoparticles, the resistivity decreases, as presented in Figure 11c. The room-temperature mobility and carrier density for different Ag concentrations, normalized by their values at zero Ag concentration, are plotted in Figure 11d. It is clearly seen that the mobility is significantly enhanced with increasing Ag concentration, whereas the carrier density is insensitive to the Ag concentration. This implies that the improvement of the conductivity by incorporating Ag nanoparticles is not due to the field effect as in the cases of the metallic ion intercalated systems. Here the mechanism is proposed as follows. In the $\mathrm{Si} / \mathrm{Ag} / \mathrm{C}$ system, there is an accumulation of charge carriers in the amorphous carbon regions between the graphite flakes because of the imbalance between the band-like transportation in the graphite flakes and the hopping transportation in the amorphous carbon regions. These accumulated charges act as scattering centers via long-range Coulomb interaction to the carriers in the graphite flakes, and therefore lower the carrier mobility for the whole system. The Ag nanoparticles embedded into the amorphous carbon regions provide extra pathways for the accumulated charges by shortening their hopping distance. As a consequence, the $\mathrm{Si} / \mathrm{Ag} / \mathrm{C}$ system has an improved transportation behavior due to the reduced scatterings among the charge carriers.

Table 6. Fitting results of the $\mathrm{Si} / \mathrm{Ag} / \mathrm{C}$ nanohybrids with different silver concentrations.

\begin{tabular}{cccc}
\hline Ag \% & $\boldsymbol{A}(\mathbf{k} \boldsymbol{\Omega} \cdot \mathbf{c m} \cdot \mathbf{K})$ & $\boldsymbol{B}(\boldsymbol{\Omega} \cdot \mathbf{c m})$ & $\boldsymbol{E}_{\boldsymbol{F}}(\mathbf{m e V})$ \\
\hline 0 & 190.4 & -149.6 & -6.0 \\
\hline
\end{tabular}




\begin{tabular}{lccc}
\hline 2.591 & 21.7 & -33.0 & -7.6 \\
3.994 & 13.4 & -13.2 & -5.5 \\
4.552 & 8.8 & -9.1 & -5.3 \\
\hline
\end{tabular}

It is worth noticing that the resistivity of the whole system decreases exponentially within the regime of low Ag concentration as suggested by Figure 11c. It indicates a significant improvement to the system's conduction by embedding the silver nanoparticles into the carbon matrix. We therefore argue that the incorporation of tiny amount of the in situ formed super-small silver nanoparticles essentially enhances the charge transportation in the amorphous carbon regions.

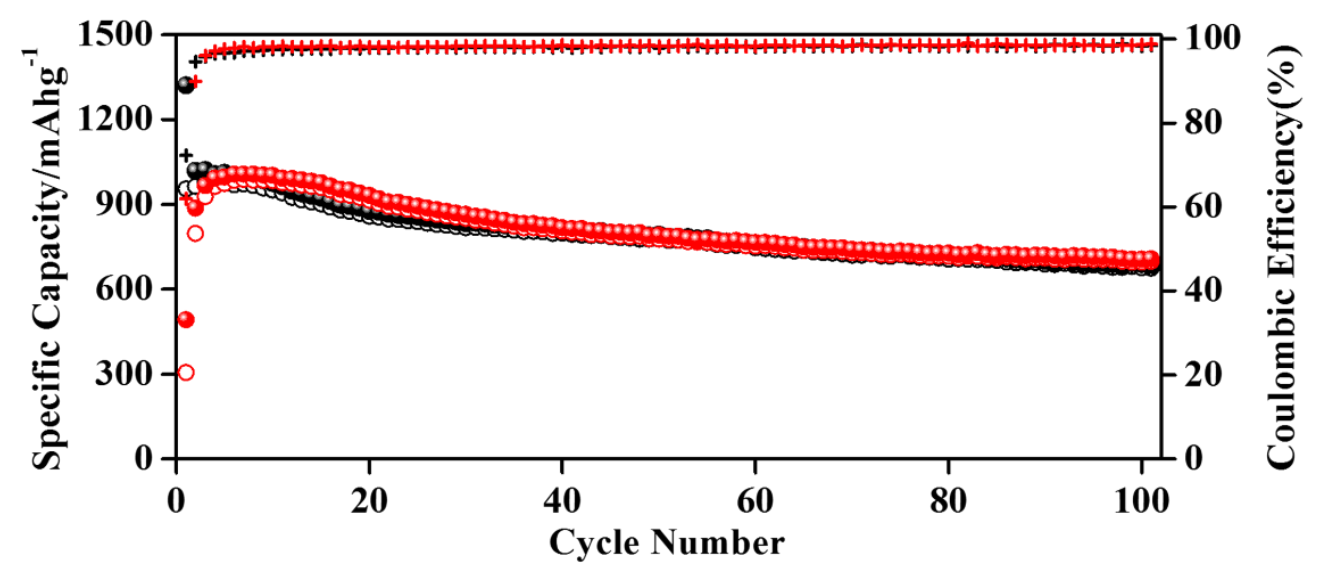

Figure 12. Cyclic performance of the $\mathrm{Si} / \mathrm{C}$ and $\mathrm{Si} / \mathrm{Ag} / \mathrm{C}$ nanohybrids. Black sphere/black open circle: discharge/charge capacity of $\mathrm{Si} / \mathrm{C}$, red sphere/red open circle: discharge/charge capacity of $\mathrm{Si} / \mathrm{Ag} / \mathrm{C}$. black cross: coulombic efficiency of Si/C, red cross: coulombic efficiency of Si/Ag/C.

The cyclic stability test is performed at a current density of $0.2 \mathrm{C}\left(1 \mathrm{C}=1000 \mathrm{mAg}^{-1}\right)$ with the voltage window between $0.005 \mathrm{~V}$ and $3.0 \mathrm{~V}\left(\mathrm{vs} . \mathrm{Li} / \mathrm{Li}^{+}\right)$. Figure 12 and Table 7 compare the cyclic performance of the $\mathrm{Si} / \mathrm{C}$ and $\mathrm{Si} / \mathrm{Ag} / \mathrm{C}$ nanohybrids. The capacity retention is calculated by dividing the capacity of the $100^{\text {th }}$ cycle with the maximum charge capacity. And the average capacity decay rate is calculated based on the expression of (1-capacity retention)/100. It is found that the incorporation of the silver nanoparticles slightly improves the cyclic stability. As detailed in Table 7, 
the initial coulombic efficiency values of the $\mathrm{Si} / \mathrm{C}$ and $\mathrm{Si} / \mathrm{Ag} / \mathrm{C}$ nanohybrids are $72.3 \%$ and $61.9 \%$ respectively. The slightly decreased initial coulombic efficiency of the $\mathrm{Si} / \mathrm{Ag} / \mathrm{C}$ nanohybrid is likely due to increased specific surface area. Furthermore, the maximum charge capacity of the $\mathrm{Si} / \mathrm{C}$ and $\mathrm{Si} / \mathrm{Ag} / \mathrm{C}$ nanohybrids are $977 \mathrm{mAhg}^{-1}$ and $988 \mathrm{mAhg}^{-1}$ respectively. And the charge capacity of the $\mathrm{Si} / \mathrm{C}$ and $\mathrm{Si} / \mathrm{Ag} / \mathrm{C}$ nanohybrids at the $100^{\text {th }}$ cycle are $674 \mathrm{mAhg}^{-1}$ and $699 \mathrm{mAhg}^{-1}$. Therefore, the capacity retention values of the $\mathrm{Si} / \mathrm{C}$ and $\mathrm{Si} / \mathrm{Ag} / \mathrm{C}$ electrode after 100 cycles reach $69 \%$ and $71 \%$ respectively corresponding to an average capacity decay rate of $0.31 \%$ and $0.29 \%$. The good cyclic stability of the $\mathrm{Si} / \mathrm{C}$ and $\mathrm{Si} / \mathrm{Ag} / \mathrm{C}$ nanohybrids results from the homogeneous embedment of the Si nanoparticles in the in situ formed continuous carbon matrix. ${ }^{55}$ The slightly improved cyclic stability of the $\mathrm{Si} / \mathrm{Ag} / \mathrm{C}$ compared to the $\mathrm{Si} / \mathrm{C}$ sample may also originate from the presence of the silver nanoparticles. The silver nanoparticles possess excellent mechanical properties and tremendous amounts of super-small silver nanoparticles exist in the $\mathrm{Si} / \mathrm{Ag} / \mathrm{C}$ nanohybrid. The silver nanoparticles can act as stress absorption center to stabilize the electrode upon huge volume change.

Table 7. Cyclic performance details of the $\mathrm{Si} / \mathrm{C}$ and $\mathrm{Si} / \mathrm{Ag} / \mathrm{C}$ depicted in Figure 11.

\begin{tabular}{cccccc}
\hline Sample & $\begin{array}{c}\text { Initial coulombic } \\
\text { efficiency }\end{array}$ & $\begin{array}{c}\text { Maximum charge } \\
\text { capacity }\end{array}$ & $\begin{array}{c}\text { Charge capacity } \\
\text { of the } \mathbf{1 0 0}^{\text {th }} \text { cycle }\end{array}$ & $\begin{array}{c}\text { Capacity } \\
\text { retention }\end{array}$ & $\begin{array}{c}\text { Average capacity } \\
\text { decay rate }(\%)\end{array}$ \\
\hline $\mathrm{Si} / \mathrm{C}$ & $72.3 \%$ & $977 \mathrm{mAhg}^{-1}$ & $674 \mathrm{mAhg}^{-1}$ & $69 \%$ & $0.31 \%$ \\
$\mathrm{Si} / \mathrm{Ag} / \mathrm{C}$ & $61.9 \%$ & $988 \mathrm{mAhg}^{-1}$ & $699 \mathrm{mAhg}^{-1}$ & $71 \%$ & $0.29 \%$ \\
\hline
\end{tabular}

The SEM and optical microscopy images in Figure 13 depict the structure change of the Si/C and $\mathrm{Si} / \mathrm{Ag} / \mathrm{C}$ nanohybrid electrodes before and after cycling test. Figure 13a shows a piece of $\mathrm{Si} / \mathrm{C}$ fragment with the size of around $2 \mu \mathrm{m}$ on the surface of the current collector. The low magnification SEM image shows that the surface of the electrode is full of micrometer-sized aggregates (Figure 13a'), which is consistent with the Figure 13a. Compared to the SEM images, 
the optical image in Figure 13a" shows that the electrode is quite homogeneous and smooth at macroscopic scale. The structures of the $\mathrm{Si} / \mathrm{C}$ electrode after cycling are depicted in the SEM images of Figure 13b, 13b', and optical image of Figure $13 b^{\prime \prime}$. Some voids are observed on the surface of the electrode (Figure 13b), which may reflect the porous structure within the electrode. The existence of the pores may be due to the volume expansion of the Si nanoparticles. Compared to the electrode before cycling test, the cycled Si/C electrode possesses more serious fragmentation as shown in Figure $13 b^{\prime}$. It indicates that the pulverization process happens caused by continuous volume change of the Si nanoparticles. Despite of the obvious structure change revealed by the SEM images, the optical image in Figure 13b" still shows homogeneous smooth surface. It indicates that the electrode still retains good structure integrity after cycles.

Figure $13 \mathrm{c}$ and Figure $13 \mathrm{c}^{\prime}$ show the morphology of the $\mathrm{Si} / \mathrm{Ag} / \mathrm{C}$ electrode before cycling. The images exhibit similar structures compared to the $\mathrm{Si} / \mathrm{C}$ electrode. The optical image of the $\mathrm{Si} / \mathrm{Ag} / \mathrm{C}$ also confirms that the electrode has excellent electrode integrity (Figure 13c"). Compared with the SEM images of the Si/C electrode after cycling, no voids are observed (Figure 13d). Figure 13d' and Figure 13d" exhibit similar structure with the Si/C electrode. It indicates that similar process takes place in the $\mathrm{Si} / \mathrm{Ag} / \mathrm{C}$ electrode along with increased cycles compared to the $\mathrm{Si} / \mathrm{C}$ electrode. This could be the reason why both $\mathrm{Si} / \mathrm{C}$ and $\mathrm{Si} / \mathrm{Ag} / \mathrm{C}$ electrodes exhibit similar cyclic performance. 


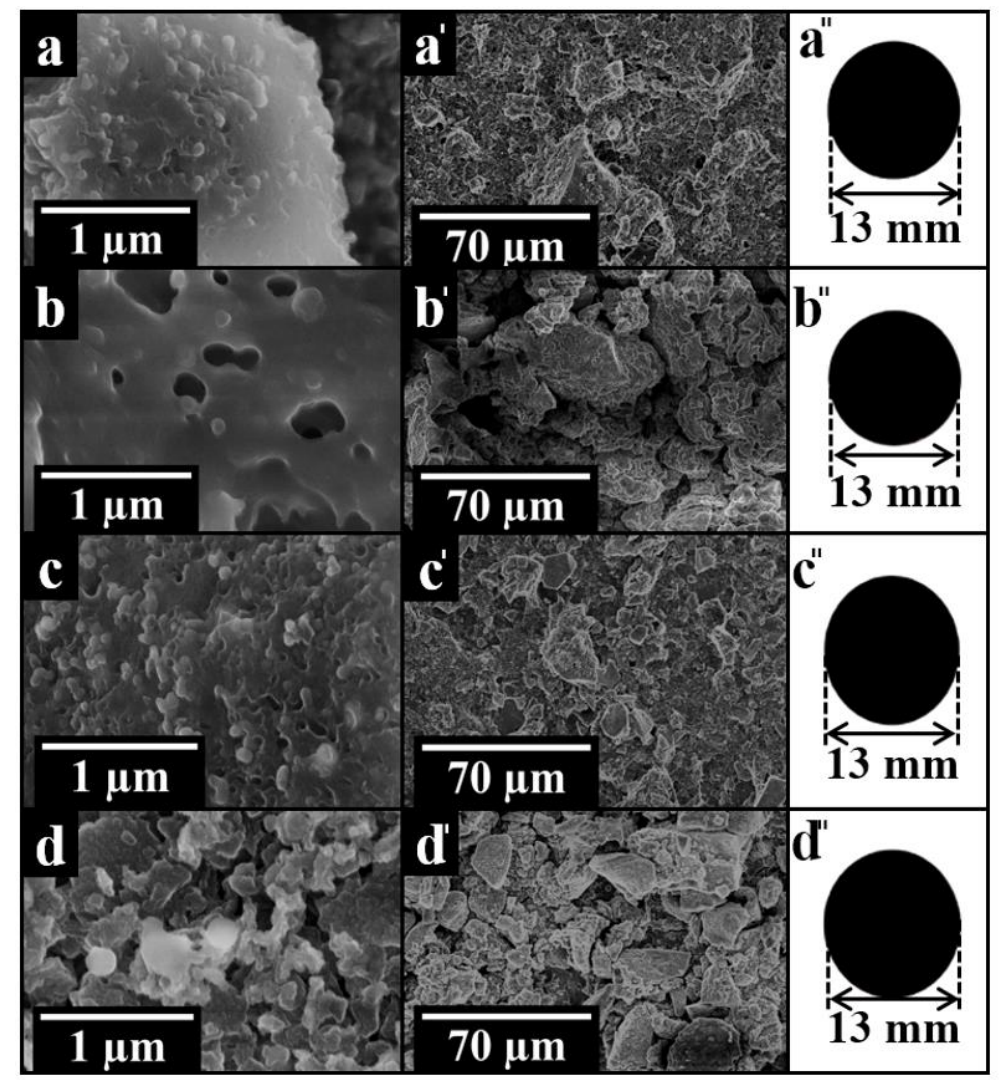

Figure 13. SEM images (a, $a^{\prime}, b, b^{\prime}, c, c^{\prime}, d$ and $\left.d^{\prime}\right)$ and photo microscopic images (a", $b^{\prime \prime}, c^{\prime \prime}$, and d") of the $\mathrm{Si} / \mathrm{C}\left(\mathrm{a}, \mathrm{a}^{\prime}, \mathrm{a}^{\prime \prime}, \mathrm{b}, \mathrm{b}^{\prime}, \mathrm{b}^{\prime \prime}\right)$ and $\mathrm{Si} / \mathrm{Ag} / \mathrm{C}\left(\mathrm{c}, \mathrm{c}^{\prime}, \mathrm{c}^{\prime \prime}, \mathrm{d}, \mathrm{d}^{\prime}, \mathrm{d}^{\prime \prime}\right)$ nanohybrid electrodes. Image a, $\mathrm{a}^{\prime}, \mathrm{a}^{\prime \prime}$, $c, c^{\prime}$ and $c^{\prime \prime}$ refer to the electrode morphology before cycling. Images $b, b^{\prime}, b^{\prime \prime}, d, d^{\prime}$ and $d^{\prime \prime}$ refer to the electrode morphology after 100 cycles.

\section{Conclusions}

A concept has been developed to improve the electrochemical performance of the silicon based lithium-ion battery anode by homogeneously incorporating the super-small metal nanoparticles into the $\mathrm{Si} / \mathrm{C}$ composite, as demonstrated by the $\mathrm{Si} / \mathrm{Ag} / \mathrm{C}$ nanohybrid anode. By using epoxy resin monomer as solvent for silicon particle dispersion and carbon source, super-small silver nanoparticles are in situ synthesized and homogeneously embedded into the in situ formed nitrogen-doped carbon matrix. The curing agent DETA is applied to dissolve silver nitrate and introduce the dissolved silver species into the epoxy resin solution. Upon polymerization, both $\mathrm{Si}$ 
nanoparticles and silver species are incorporated into the thermosetting epoxy polymer network. Through calcination in argon atmosphere at $800{ }^{\circ} \mathrm{C}$, super-small silver nanoparticles with the average diameter of $2.9 \mathrm{~nm}$ are in situ synthesized and the thermosetting epoxy polymer is simultaneously transformed into a continuous nitrogen doped carbon matrix. The structure, morphology, crystallinity, and porosity of the $\mathrm{Si} / \mathrm{C}$ and $\mathrm{Si} / \mathrm{Ag} / \mathrm{C}$ nanohybrids are systematically investigated by XRD, Raman, FTIR, TGA, TEM, EDX, nitrogen adsorption-desorption measurement, XPS, and SAXS. The electrochemical performance of the $\mathrm{Si} / \mathrm{C}$ and $\mathrm{Si} / \mathrm{Ag} / \mathrm{C}$ nanohybrid as lithium-ion battery anodes are tested. A significant rate performance improvement is achieved with incorporation of tiny amount of the super-small silver nanoparticles $(2.59 \%$ by mass). The existence of the super-small silver nanoparticles effectively enhances the electron transportation within the electrode as confirmed by both EIS measurement and theoretical calculation. The mechanism for the enhanced rate performance is also investigated by uncovering the temperature dependent electron conductivity behavior of the $\mathrm{Si} / \mathrm{Ag} / \mathrm{C}$ nanohybrids with different silver concentrations. It proves that the incorporation of the super-small silver nanoparticles in the carbon matrix leads to a significantly enhanced charge carrier mobility. Besides the rate performance, the $\mathrm{Si} / \mathrm{Ag} / \mathrm{C}$ nanohybrid also exhibits slightly improved cyclic stability that the $\mathrm{Si} / \mathrm{C}$ sample. The Si nanoparticles are well embedded in the buffer medium of continuous carbon matrix containing silver nanoparticles. The tremendous amounts of super-small silver nanoparticles with excellent mechanical properties may act as stress absorption centers to help stabilize the electrode upon drastic volume change. The work presented in this manuscript is in principle universally applicable to other metal system and provide a way to improve the electrochemical performance of the silicon based lithium-ion battery anode with tiny amount of metal species. 


\section{METHODS}

\section{Materials}

All chemicals were used as received without further purification. $\mathrm{AgNO}_{3}(99.8 \%)$ were purchased from Aladdin Reagent Co., Ltd., Shanghai, China. Silicon nanoparticles (30 nm, $99.9 \%$ ) were bought from HT-NANO Shanghai, China. Diethylenetriamine (DETA, $\geq 98 \%$ ) was obtained from Damao Chemical Reagent, Tianjin, China. Epoxy resin (DER331) was purchased from DOW. USA. Sodium alginate was obtained from Aladdin Reagent Co., Ltd., China. Conductive carbon Super P was bought from SCM Chem. Shanghai, China.

\section{Sample Synthesis}

The synthesis of the $\mathrm{Si} / \mathrm{Ag} / \mathrm{C}$ nanohybrid is described as follows: $\mathrm{AgNO}_{3}$ (0.3 gram) was dissolved in DETA (diethylenetriamine, 1.47 gram) through ultrasonication $(60 \mathrm{~W}, 2 \mathrm{~h}$ ) at room temperature until a clear light yellow solution was observed. Meanwhile, Si nanoparticles (1 gram) were dispersed in an epoxy resin solution (DER331, 10 gram) with stirring at $80{ }^{\circ} \mathrm{C}$ to form a homogeneous suspension. Thereafter, the curing agent solution containing $\mathrm{AgNO}_{3}$ and DETA was poured into the Si/DER 331 suspension accompanied by manual stirring at room temperature to keep homogeneous dispersion. The mixture was then transferred to a PTFE mould, followed by polymerization at $80{ }^{\circ} \mathrm{C}$ for 30 minutes. The as-polymerized composites were smashed into small particulate powders with a mixer. Calcination in argon atmosphere was performed at $800{ }^{\circ} \mathrm{C}$ for 4 hours in a tube furnace with a ramp rate of $5 \mathrm{~K} / \mathrm{min}$ starting from room temperature, followed by natural cooling to room temperature. The calcined samples were then ball milled with a planetary ball miller (FRITSCH-pulverisette 7, Germany) for 4 hours with the speed of $400 \mathrm{rpm}$, followed by sieving with a 300 mesh sieve. The control sample of the Si/C nanohybrid was prepared with the 
same protocol except no silver nitrate was used. The Si/Ag/C nanohybrids with different silver compositions were synthesized with similar protocols where the feeding amount of the silver nitrate was tuned. The exact amount of the diethylenetriamine used was calculated based on the epoxy value of the epoxy resin. ${ }^{47}$

\section{Sample Characterization}

The curing degree of the epoxy resin was evaluated with soxhlet extraction in acetone, which was performed at $100{ }^{\circ} \mathrm{C}$ for 48 hours. X-ray diffraction (XRD) characterization was performed on a diffractometer (Bruker AXS D8 Advance, $\lambda=1.541 \AA, 2.2 \mathrm{~kW}$ ) with 2 theta range from $5{ }^{\circ}$ to $90^{\circ}$. The EDX elemental mapping was carried out with FEI QUANTA 250 FEG (America FEI) at an accelerating voltage of $15 \mathrm{kV}$. The microstructure images of the electrodes were obtained with Hitachi S4800 scanning electron microscope (Tokyo, Japan) at an accelerating voltage of $4 \mathrm{kV}$. TEM experiment was performed with a JEOL JEM-2100F TEM or Tecnai F20 (America FEI) instrument operated at $200 \mathrm{kV}$. The specific surface area measurement was carried out based on $\mathrm{N}_{2}$ adsorption desorption test with Micromeritics ASAP2020 Accelerated Surface Area and Porosimetry System. The carbon contents of the samples were determined by a thermogravimetric analyzer (TGA, Mettler Toledo, Switzerland) in air atmosphere, the temperature range was set between $50{ }^{\circ} \mathrm{C}$ and $800{ }^{\circ} \mathrm{C}$ and the ramp rate was $20 \mathrm{~K} / \mathrm{min}$. Raman spectroscopy was collected on a Renishaw (in Via-reflex) with the excitation wavelength of $532 \mathrm{~nm}$. Fourier transform infrared (FTIR) analysis was performed on a Nicolet 6700 infrared spectrometer. The spectra $\left(4000 \mathrm{~cm}^{-1}-\right.$ $400 \mathrm{~cm}^{-1}$ ) were recorded with a resolution of $0.9 \mathrm{~cm}^{-1}$ and 32 scans per sample. The silver content in $\mathrm{Si} / \mathrm{Ag} / \mathrm{C}$ nanohybrid was measured by inductively coupled plasma optical emission spectrometer (ICP-OES, Perkin-Elmer, USA). Specifically, $0.01 \mathrm{~g}$ of the $\mathrm{Si} / \mathrm{Ag} / \mathrm{C}$ power was added to a digestion 
high-pressure tank with $8 \mathrm{ml} \mathrm{HCl}(36 \%-38 \%), 0.5 \mathrm{ml} \mathrm{HClO}_{4}(70 \%-72 \%), 0.5 \mathrm{ml} \mathrm{H}_{2} \mathrm{O}_{2}(\geq 30 \%)$ and $0.5 \mathrm{ml} \mathrm{HF}$ ( $\geq 40 \%$ ). The digestion process was performed at $180{ }^{\circ} \mathrm{C}$ for $4 \mathrm{~h}$. Small-angle X-ray scattering (SAXS) measurements were performed using a Ganesha 300XL SAXS-WAXS system (SAXS LAB ApS, Copenhagen/Denmark) with an X-ray wavelength of $0.154 \mathrm{~nm}$. The detector was positioned at a distance of $406 \mathrm{~mm}$ from the sample. Glass capillaries were used as sample containers for the SAXS measurements. X-ray photoelectron spectroscopy (XPS) measurement was done with an ESCALAB 250Xi spectrometer, using focused monochromatized Al Ka radiation (hv $=1486.6 \mathrm{eV}$ ) at room temperature. I-V measurement was carried out on Physical Property Measurement System (Model 9, USA) with a temperature range between $100 \mathrm{~K}$ and $300 \mathrm{~K}$. The test current was $0.1 \mathrm{~mA}$ and frequency was $60 \mathrm{~Hz}$. The silver paste (H20E silver epoxy) used on connecting wires was brought from EPO-TEK Co., Ltd. $0.1 \mathrm{~g}$ active material and $1.0 \mathrm{~g} \mathrm{KBr}$ were fully mixed and ground in an agate mortar. Thereafter, the mixture powder was pressed into a pellet using an infrared press machine with a pressure of $20 \mathrm{MPa}$. The pellet was carved into a rectangular shape of $7 \mathrm{~mm} \times 2 \mathrm{~mm}$.

\section{Electrode Fabrication}

The active material, sodium alginate, and super $\mathrm{P}$ were thoroughly mixed together in mortar with a composition of 7:2:1 by mass in water. Thereafter, the slurry was spread onto a copper foil by doctor blading, followed by drying in oven at $40{ }^{\circ} \mathrm{C}$ for 4 hours. After drying the copper foil was pressed, and cut into spherical electrodes with the diameter of $13 \mathrm{~mm}$. The actual mass loading of the active material on different electrodes are listed in Table 2. The mass loaded on the copper foil was weighed using a balance with a resolution of $0.01 \mathrm{mg}$. After weighing, the electrodes were stored in oven at $80{ }^{\circ} \mathrm{C}$ for 4 hours before coin cell assembly. Coin type cells (CR2032) were 
assembled in a glove box (MB-10-compact, MBRAUN) filled with Argon. The oxygen and water contents were monitored to be less than $0.5 \mathrm{ppm}$. Li metal foil was applied as counter electrode and Celgard 2300 was used as separator respectively. Commercial electrolyte from Dongguan Shanshan Co., Ltd was used, where $1 \mathrm{M} \mathrm{LiPF}_{6}$ was dissolved in a mixture of ethylene carbonate (EC) and diethyl carbonate (DEC) with a volume ratio of 1:1. After assembly the coin cells were aged for 24 hours before electrochemical performance test.

Table 2. Mass loading density of the electrodes with respect to the active material.

\begin{tabular}{ccc}
\hline \multirow{2}{*}{ Testing condition } & \multicolumn{2}{c}{ mass loading density of the active material $\mathbf{m g c m}^{-2}$} \\
\cline { 2 - 3 } & $\mathbf{S i} / \mathbf{C}$ electrode $\left(\mathbf{m}_{\mathrm{Si} / \mathrm{C}}\right)$ & $\mathbf{S i} / \mathbf{A g} / \mathbf{C}$ electrode $\left(\mathbf{m}_{\mathrm{Si} / \mathrm{Ag} / \mathbf{C}}\right)$ \\
\hline cycling performance test & 1.32 & 1.13 \\
rate performance test & 1.25 & 1.21 \\
\hline
\end{tabular}

\section{Electrochemical Test}

The cells were discharged and charged on a battery tester (LAND2001A, China) between $0.005 \mathrm{~V}$ and $3.0 \mathrm{~V}$ (vs. $\left.\mathrm{Li} / \mathrm{Li}^{+}\right)$with a current density of $0.2 \mathrm{C}\left(1 \mathrm{C}=1000 \mathrm{~mA} \mathrm{~g}{ }^{-1}\right)$ at room temperature. The rate performance was measured at a current density sequence of $0.1 \mathrm{C}, 0.2 \mathrm{C}, 0.5$ $\mathrm{C}, 1.0 \mathrm{C}$ and $0.1 \mathrm{C}$ in the voltage range between $0.005 \mathrm{~V}$ and $3.0 \mathrm{~V}\left(\mathrm{vs} \mathrm{Li} / \mathrm{Li}^{+}\right.$) (five cycles each current density). The lithiation process was defined as discharge process and the corresponding delithiation process was indexed as charge process. The electrochemical impedance spectroscopy (EIS) measurements were performed over a frequency range from $10 \mathrm{kHz}$ to $0.001 \mathrm{~Hz}$. The CHI 1040B potentiostat/galvanostat analyzer (Shanghai Chenhua instrument Co., Ltd.) was used to conduct the cyclic voltammetry test at a scanning rate of $0.2 \mathrm{mV} / \mathrm{s}$ with the voltage range between $0.001 \mathrm{~V}$ and $3.0 \mathrm{~V}$. It is reported that the lithiation of silver mainly occurs below $0.07 \mathrm{~V}$ and the alloying/de-alloying process between $\mathrm{Ag}$ and $\mathrm{Li}$ is difficult. ${ }^{37,78}$ Therefore the lithiation of the silver 
nanoparticles during the repeated cycling is neglected. The specific capacity is calculated based on the mass of the Si and carbon content in both samples.

\section{ASSOCIATED CONTENT}

\section{Supporting Information}

The Supporting Information is available free of charge on the ACS publications website. I-V curves of the $\mathrm{Si} / \mathrm{Ag} / \mathrm{C}$ nanohybrids with different silver compositions.

\section{AUTHOR INFORMATION}

\section{Corresponding Author}

*E-mail: chengyj@nimte.ac.cn

\section{ORCID}

Yonggao Xia: 0000-0003-4901-1176

Ya-Jun Cheng: 0000-0002-0932-295X

\section{Notes}

The authors declare no competing financial interest.

\section{Acknowledgement}

The authors would like to thank Prof. Dr. Xile Hu for the fruitful scientific discussions. This research is funded by the National Key R\&D Program of China (Grant No. 2016YFB0100100), Natural Science Foundation of China (51103172, 51702335), the Zhejiang Nonprofit Technology Applied Research Program (2013C33190), and the open project of the Beijing National Laboratory for Molecular Science (20140138), the CAS-EU S\&T cooperation partner program (174433KYSB20150013) and Key Laboratory of Bio-based Polymeric Materials of Zhejiang Province. S.X. acknowledges the China Scholarship Council (CSC) and P.M-B acknowledges 
funding by the International Research Training Group 2022 Alberta/Technical University of Munich International Graduate School for Environmentally Responsible Functional Hybrid Materials (ATUMS). 


\section{References}

1. Armand, M.; Tarascon, J. M. Building Better Batteries. Nature 2008, 451, 652-657.

2. Chen, T.; Qiu, L.; Yang, Z.; Cai, Z.; Ren, J.; Li, H.; Lin, H.; Sun, X.; Peng, H. An Integrated "Energy Wire" for Both Photoelectric Conversion and Energy Storage. Angew. Chem., Int. Ed. 2012, 51, 11977-11980.

3. Roy, P.; Srivastava, S. K. Nanostructured Anode Materials for Lithium Ion Batteries. J. Mater. Chem. A 2015, 3, 2454-2484.

4. Park, D.-W.; Jeong, Y.; PremKumar, T.; Lee, J. Quasi-Photonic Crystal Effect of Ticl3/Electrolyte Matrix in Unipolar Dye-Absorber Devices. ACS Appl. Mater. Interfaces 2014, 6, 14399-14404.

5. Tollefson, J. Car Industry: Charging up the Future. Nature 2008, 456, 436-440.

6. Dunn, B.; Kamath, H.; Tarascon, J.-M. Electrical Energy Storage for the Grid: A Battery of Choices. Science 2011, 334, 928-935.

7. Kim, J. W.; Ocon, J. D.; Park, D.-W.; Lee, J. Functionalized Graphene-Based Cathode for Highly Reversible Lithium-Sulfur Batteries. ChemSusChem 2014, 7, 1265-1273.

8. Kaskhedikar, N. A.; Maier, J. Lithium Storage Ion Carbon Nanostructures. Adv. Mater.2009, 21, 2664-2680.

9. Szczech, J. R.; Jin, S. Nanostructured Silicon for High Capacity Lithium Battery Anodes. Energy Environ. Sci. 2011, 4, 56-72.

10. Ge, M.; Fang, X.; Rong, J.; Zhou, C. Review of Porous Silicon Preparation and Its Application for Lithium-lon Battery Anodes. Nanotechnology 2013, 24.

11. Zamfir, M. R.; Hung Tran, N.; Moyen, E.; Lee, Y. H.; Pribat, D. Silicon Nanowires for Li-Based Battery Anodes: A Review. J. Mater. Chem. A 2013, 1, 9566-9586.

12. Su, X.; Wu, Q.; Li, J.; Xiao, X.; Lott, A.; Lu, W.; Sheldon, B. W.; Wu, J. Silicon-Based Nanomaterials for Lithium-Ion Batteries: A Review. Adv. Energy Mater. 2014, 4.

13. Kim, N.; Chae, S.; Ma, J.; Ko, M.; Cho, J. Fast-Charging High-Energy Lithium-Ion Batteries Via Implantation of Amorphous Silicon Nanolayer in Edge-Plane Activated Graphite Anodes. Nat. Commun. 2017, 8.

14. Pietsch, P.; Westhoff, D.; Feinauer, J.; Eller, J.; Marone, F.; Stampanoni, M.; Schmidt, V.; Wood, V. Quantifying Microstructural Dynamics and Electrochemical Activity of Graphite and Silicon-Graphite Lithium Ion Battery Anodes. Nat. Commun. 2016, 7.

15. Xiao, Q.; Gu, M.; Yang, H.; Li, B.; Zhang, C.; Liu, Y.; Liu, F.; Dai, F.; Yang, L.; Liu, Z.; Xiao, X.; Liu, G.; Zhao, P.; Zhang, S.; Wang, C.; Lu, Y.; Cai, M. Inward Lithium-Ion Breathing of Hierarchically Porous Silicon Anodes. Nat. Commun. 2015, 6.

16. Wang, X.; Fan, F.; Wang, J.; Wang, H.; Tao, S.; Yang, A.; Liu, Y.; Chew, H. B.; Mao, S. X.; Zhu, T.; Xia, S. High Damage Tolerance of Electrochemically Lithiated Silicon. Nat. Commun. 2015, 6.

17. Piper, D. M.; Evans, T.; Leung, K.; Watkins, T.; Olson, J.; Kim, S. C.; Han, S. S.; Bhat, V.; Oh, K. H.; Buttry, D. A.; Lee, S.-H. Stable Silicon-Ionic Liquid Interface for Next-Generation Lithium-Ion Batteries. Nat. Commun. 2015, 6.

18. Li, X.; Gu, M.; Hu, S.; Kennard, R.; Yan, P.; Chen, X.; Wang, C.; Sailor, M. J.; Zhang, J.-G.; Liu, J. Mesoporous Silicon Sponge as an Anti-Pulverization Structure for High-Performance Lithium-Ion Battery Anodes. Nat. Commun. 2014, 5.

19. Wu, H.; Yu, G.; Pan, L.; Liu, N.; McDowell, M. T.; Bao, Z.; Cui, Y. Stable Li-lon Battery Anodes by in-Situ Polymerization of Conducting Hydrogel to Conformally Coat Silicon Nanoparticles. Nat. 


\section{Commun. 2013, 4.}

20. Liu, X. H.; Zhong, L.; Huang, S.; Mao, S. X.; Zhu, T.; Huang, J. Y. Size-Dependent Fracture of Silicon Nanoparticles During Lithiation. ACS Nano 2012, 6, 1522-1531.

21. Shi, F.; Song, Z.; Ross, P. N.; Somorjai, G. A.; Ritchie, R. O.; Komvopoulos, K. Failure Mechanisms of Single-Crystal Silicon Electrodes in Lithium-Ion Batteries. Nat. Commun. 2016, 7.

22. Lee, S. W.; Lee, H.-W.; Ryu, I.; Nix, W. D.; Gao, H.; Cui, Y. Kinetics and Fracture Resistance of Lithiated Silicon Nanostructure Pairs Controlled by Their Mechanical Interaction. Nat. Commun. 2015, 6.

23. Wu, H.; Cui, Y. Designing Nanostructured Si Anodes for High Energy Lithium Ion Batteries. Nano Today 2012, 7, 414-429.

24. Li, Y. Z.; Yan, K.; Lee, H. W.; Lu, Z. D.; Liu, N.; Cui, Y. Growth of Conformal Graphene Cages on Micrometre-Sized Silicon Particles as Stable Battery Anodes. Nat. Energy 2016, 1.

25. Zuo, X.; Zhu, J.; Müller-Buschbaum, P.; Cheng, Y.-J. Silicon Based Lithium-Ion Battery Anodes: A Chronicle Perspective Review. Nano Energy 2017, 31, 113-143.

26. Song, J.; Chen, S.; Zhou, M.; Xu, T.; Lv, D.; Gordin, M. L.; Long, T.; Melnyk, M.; Wang, D. Micro-Sized Silicon-Carbon Composites Composed of Carbon-Coated Sub-10 Nm Si Primary Particles as High-Performance Anode Materials for Lithium-Ion Batteries. J. Mater. Chem. A 2014, 2, 1257-1262.

27. Kim, H.; Seo, M.; Park, M.-H.; Cho, J. A Critical Size of Silicon Nano-Anodes for Lithium Rechargeable Batteries. Angew. Chem., Int. Ed. 2010, 49, 2146-2149.

28. Ni, S.; Lv, X.; Li, T.; Yang, X.; Zhang, L.; Ren, Y. A Novel Electrochemical Activation Effect Induced Morphology Variation from Massif-Like Cuxo to Forest-Like Cu2o Nanostructure and the Excellent Electrochemical Performance as Anode for Li-Ion Battery. Electrochim. Acta 2013, 96, 253-260.

29. Hou, X.; Zhang, M.; Wang, J.; Hu, S.; Liu, X. Deposition of Silver Nanoparticles into Silicon/Carbon Composite as a High-Performance Anode Material for Li-Ion Batteries. J. Solid State Electrochem. 2015, 19, 3595-3604.

30. Zhang, F.; Yang, X.; Xie, Y.; Yi, N.; Huang, Y.; Chen, Y. Pyrolytic Carbon-Coated Si Nanoparticles on Elastic Graphene Framework as Anode Materials for High-Performance Lithium-Ion Batteries. Carbon 2015, 82, 161-167.

31. Wang, B.; Li, X.; Zhang, X.; Luo, B.; Jin, M.; Liang, M.; Dayeh, S. A.; Picraux, S. T.; Zhi, L. Adaptable Silicon-Carbon Nanocables Sandwiched between Reduced Graphene Oxide Sheets as Lithium Ion Battery Anodes. ACS Nano 2013, 7, 1437-1445.

32. Yu, J.; Zhan, H.; Wang, Y.; Zhang, Z.; Chen, H.; Li, H.; Zhong, Z.; Su, F. Graphite Microspheres Decorated with Si Particles Derived from Waste Solid of Organosilane Industry as High Capacity Anodes for Li-Ion Batteries. J. Power Sources 2013, 228, 112-119.

33. Wang, W.; Kumta, P. N. Nanostructured Hybrid Silicon/Carbon Nanotube Heterostructures: Reversible High-Capacity Lithium-Ion Anodes. ACS Nano 2010, 4, 2233-2241.

34. Tao, H.; Fan, L.-Z.; Song, W.-L.; Wu, M.; He, X.; Qu, X. Hollow Core-Shell Structured Si/C Nanocomposites as High-Performance Anode Materials for Lithium-Ion Batteries. Nanoscale 2014, 6, 3138-3142.

35. Yang, X.; Wen, Z.; Huang, S.; Zhu, X.; Zhang, X. Electrochemical Performances of Silicon Electrode with Silver Additives. Solid State Ionics 2006, 177, 2807-2810.

36. Ohara, S.; Suzuki, J.; Sekine, K.; Takamura, T. Li Insertion/Extraction Reaction at a Si Film Evaporated on a Ni Foil. J. Power Sources 2003, 119-121, 591-596. 
37. Talla, G.; Guduru, R. K.; Li, B. Q.; Mohanty, P. S. Doped-Si-Ag Composite Electrodes for Li-Ion Batteries. Solid State Ionics 2015, 269, 8-13.

38. Liu, Y.; Chen, B.; Cao, F.; Chan, H. L. W.; Zhao, X.; Yuan, J. One-Pot Synthesis of Three-Dimensional Silver-Embedded Porous Silicon Micronparticles for Lithium-Ion Batteries. J. Mater. Chem. 2011, 21, 17083.

39. Cheng, Y.; Yi, Z.; Wang, C. L.; Wang, L. D.; Wu, Y. M.; Wang, L. M. Influence of Copper Addition for Silicon-Carbon Composite as Anode Materials for Lithium Ion Batteries. RSC Adv. 2016, 6, S6756-S6764.

40. Wang, N.; Hang, T.; Ling, H. Q.; Hu, A. M.; Li, M. High-Performance Si-Based 3d Cu Nanostructured Electrode Assembly for Rechargeable Lithium Batteries. J. Mater. Chem. A 2015, 3, 11912-11919.

41. Meng, X. H.; Deng, D. Core-Shell Ti@Si Coaxial Nanorod Arrays Formed Directly on Current Collectors for Lithium-Ion Batteries. ACS Appl. Mater. Interfaces 2015, 7, 6867-6874.

42. Zhao, W. J.; Du, N.; Xiao, C. M.; Wu, H.; Zhang, H.; Yang, D. R. Large-Scale Synthesis of Ag-Si Core-Shell Nanowall Arrays as High-Performance Anode Materials of Li-Ion Batteries. J. Mater. Chem. A 2014, 2, 13949-13954.

43. Chen, D.; Mei, X.; Ji, G.; Lu, M.; Xie, J.; Lu, J.; Lee, J. Y. Reversible Lithium-lon Storage in Silver-Treated Nanoscale Hollow Porous Silicon Particles. Angew. Chem., Int. Ed. 2012, 51, 2409-2413.

44. Cao, F. F.; Deng, J. W.; Xin, S.; Ji, H. X.; Schmidt, O. G.; Wan, L. J.; Guo, Y. G. Cu-Si Nanocable Arrays as High-Rate Anode Materials for Lithium-Ion Batteries. Adv. Mater.2011, 23, 4415-+.

45. Zhang, S. C.; Du, Z. J.; Lin, R. X.; Jiang, T.; Liu, G. R.; Wu, X. M.; Weng, D. S. Nickel Nanocone-Array Supported Silicon Anode for High-Performance Lithium-Ion Batteries. Adv. Mater.2010, 22, 5378-+.

46. Yu, Y.; Gu, L.; Zhu, C.; Tsukimoto, S.; van Aken, P. A.; Maier, J. Reversible Storage of Lithium in Silver-Coated Three-Dimensional Macroporous Silicon. Adv. Mater.2010, 22, 2247-+.

47. Kim, J. W.; Ryu, J. H.; Lee, K. T.; Oh, S. M. Improvement of Silicon Powder Negative Electrodes by Copper Electroless Deposition for Lithium Secondary Batteries. J. Power Sources 2005, 147, 227-233.

48. Cheng, Y.-J.; Zeiger, D. N.; Howarter, J. A.; Zhang, X.; Lin, N. J.; Antonucci, J. M.; Lin-Gibson, S. In Situ Formation of Silver Nanoparticles in Photocrosslinking Polymers. J. Biomed. Mater. Res., Part $B$ 2011, 97B, 124-131.

49. Tang, H.; Xia, X. H.; Zhang, Y. J.; Tong, Y. Y.; Wang, X. L.; Gu, C. D.; Tu, J. P. Binary Conductive Network for Construction of $\mathrm{Si} / \mathrm{Ag}$ Nanowires/Rgo Integrated Composite Film by Vacuum-Filtration Method and Their Application for Lithium Ion Batteries. Electrochim. Acta 2015, 180, 1068-1074.

50. Kwon, E.; Lim, H.-S.; Sun, Y.-K.; Suh, K.-D. Improved Rate Capability of Lithium-Ion Batteries with Ag Nanoparticles Deposited onto Silicon/Carbon Composite Microspheres as an Anode Material. Solid State Ionics 2013, 237, 28-33.

51. Su, M.; Wang, Z.; Guo, H.; Li, X.; Huang, S.; Xiao, W.; Gan, L. Enhancement of the Cyclability of a Si/Graphite@Graphene Composite as Anode for Lithium-Ion Batteries. Electrochim. Acta 2014, 116, 230-236.

52. Xiao, Y.; Wang, X. Y.; Xia, Y. G.; Yao, Y.; Metwalli, E.; Zhang, Q.; Liu, R.; Qiu, B.; Rasool, M.; Liu, Z. P.; Meng, J. Q.; Sun, L. D.; Yan, C. H.; Mueller-Buschbaum, P.; Cheng, Y. J. Green Facile Scalable Synthesis of Titania/Carbon Nanocomposites: New Use of Old Dental Resins. ACS Appl. Mater. 
Interfaces 2014, 6, 18461-18468.

53. Wang, X.; Meng, J. Q.; Wang, M.; Xiao, Y.; Liu, R.; Xia, Y.; Yao, Y.; Metwalli, E.; Zhang, Q.; Qiu, B.; Liu, Z.; Pan, J.; Sun, L. D.; Yan, C. H.; Muller-Buschbaum, P.; Cheng, Y. J. Facile Scalable Synthesis of Tio2/Carbon Nanohybrids with Ultrasmall Tio2 Nanoparticles Homogeneously Embedded in Carbon Matrix. ACS Appl Mater Interfaces 2015, 7, 24247-55.

54. Wang, M.; Xia, Y.; Wang, X.; Xiao, Y.; Zhang, Q.; Liu, R.; Qiu, B.; Wu, Q.; Chen, G.; Liu, Y.; Yang, Z.; Liu, Z.; Meng, J. Q.; Sun, L. D.; Yan, C. H.; Pan, J.; Cheng, Y. J. Facile Scalable Synthesis of Sioc/Carbon Nanohybrids as Lithium-Ion Battery Anode Inspired by Dental Restorative Materials. Dig J Nanomater Bios 2016, 11, 567-578.

55. Wang, M.; Xia, Y.; Wang, X.; Xiao, Y.; Liu, R.; Wu, Q.; Qiu, B.; Metwalli, E.; Xia, S.; Yao, Y.; Chen, G.; Liu, Y.; Liu, Z.; Meng, J. Q.; Yang, Z.; Sun, L. D.; Yan, C. H.; Muller-Buschbaum, P.; Pan, J.; Cheng, Y. J. Silicon Oxycarbide/Carbon Nanohybrids with Tiny Silicon Oxycarbide Particles Embedded in Free Carbon Matrix Based on Photoactive Dental Methacrylates. ACS Appl Mater Interfaces 2016, 8, 13982-92.

56. Li, W.; Cao, K.; Wang, H.; Liu, J.; Zhou, L.; Yao, H. Carbon Coating May Expedite the Fracture of Carbon-Coated Silicon Core-Shell Nanoparticles During Lithiation. Nanoscale 2016, 8, 5254-9.

57. Faria, A. F.; Martinez, D. S. T.; Moraes, A. C. M.; Maia da Costa, M. E. H.; Barros, E. B.; Souza Filho, A. G.; Paula, A. J.; Alves, O. L. Unveiling the Role of Oxidation Debris on the Surface Chemistry of Graphene through the Anchoring of Ag Nanoparticles. Chem. Mater. 2012, 24, 4080-4087.

58. Zhou, W.; Upreti, S.; Whittingham, M. S. Electrochemical Performance of Al-Si-Graphite Composite as Anode for Lithium-Ion Batteries. Electrochem. Commun. 2011, 13, 158-161.

59. Wang, Y.; Su, F.; Wood, C. D.; Lee, J. Y.; Zhao, X. S. Preparation and Characterization of Carbon Nanospheres as Anode Materials in Lithium-Ion Secondary Batteries. Ind. Eng. Chem. Res. 2008, 47, 2294-2300.

60. Deshmukh, P.; Peshwe, D.; Pathak, S. FTIR and TGA Analysis in Relation with the \% Crystallinity of the $\mathrm{SiO}_{2}$ Obtained by Burning Rice Husk at Various Temperatures. Adv. Mater. Res 2012, 585, 77-81.

61. Ban, J.; Yang, P.; Xiaa, Y.; Wang, M.; Wang, X.; Xiao, Y.; Qiu, B.; Yang, L.; Liu, Z.; Zhu, C.; Chen, C.; Cheng, Y. J. Facile Synthesis of Mno/Carbon/Carbon Nanotube Nanohybrids Using Dental Resins as Solvent and Carbon Source. Dig J Nanomater Bios 2016, 11, 223-234.

62. Wang, L.; Dou, S.; Xu, J. T.; Liu, H. K.; Wang, S. Y.; Ma, J. M.; Dou, S. X. Highly Nitrogen Doped Carbon Nanosheets as an Efficient Electrocatalyst for the Oxygen Reduction Reaction. Chem. Commun. 2015, 51, 11791-11794.

63. Li, X.; Feng, Y.; Li, M.; Li, W.; Wei, H.; Song, D. Smart Hybrids of Zn2geo4nanoparticles and Ultrathin G-C3n4layers: Synergistic Lithium Storage and Excellent Electrochemical Performance. Adv. Funct. Mater. 2015, 25, 6858-6866.

64. Sheng, Z. H.; Shao, L.; Chen, J. J.; Bao, W. J.; Wang, F. B.; Xia, X. H. Catalyst-Free Synthesis of Nitrogen-Doped Graphene Via Thermal Annealing Graphite Oxide with Melamine and Its Excellent Electrocatalysis. ACS Nano 2011, 5, 4350-4358.

65. Li, J.; Dahn, J. R. An in Situ X-Ray Diffraction Study of the Reaction of Li with Crystalline Si. J. Electrochem. Soc. 2007, 154, A156-A161.

66. Du, F.-H.; Wang, K.-X.; Fu, W.; Gao, P.-F.; Wang, J.-F.; Yang, J.; Chen, J.-S. A Graphene-Wrapped Silver-Porous Silicon Composite with Enhanced Electrochemical Performance for Lithium-Ion 
Batteries. J. Mater. Chem. A 2013, 1, 13648-13654.

67. Obrovac, M. N.; Krause, L. J. Reversible Cycling of Crystalline Silicon Powder. J. Electrochem. Soc. 2007, 154, A103-A108.

68. Xiao, W.; Wang, Z.; Guo, H.; Li, X.; Wang, J.; Huang, S.; Gan, L. Fe2o3 Particles Enwrapped by Graphene with Excellent Cyclability and Rate Capability as Anode Materials for Lithium Ion Batteries. Appl. Surf. Sci. 2013, 266, 148-154.

69. Liu, Y.; Hanai, K.; Yang, J.; Imanishi, N.; Hirano, A.; Takeda, Y. Morphology-Stable Silicon-Based Composite for Li-Intercalation. Solid State Ionics 2004, 168, 61-68.

70. Kong, J.; Yee, W. A.; Wei, Y.; Yang, L.; Ang, J. M.; Phua, S. L.; Wong, S. Y.; Zhou, R.; Dong, Y.; Li, X.; Lu, X. Silicon Nanoparticles Encapsulated in Hollow Graphitized Carbon Nanofibers for Lithium Ion Battery Anodes. Nanoscale 2013, 5, 2967-2973.

71. Kim, H.; Cho, J. Superior Lithium Electroactive Mesoporous Si@Carbon Core-Shell Nanowires for Lithium Battery Anode Material. Nano Lett. 2008, 8, 3688-3691.

72. Limthongkul, P.; Jang, Y. I.; Dudney, N. J.; Chiang, Y. M. Electrochemically-Driven Solid-State Amorphization in Lithium-Silicon Alloys and Implications for Lithium Storage. Acta Mater. 2003, 51, 1103-1113.

73. Yoo, S.; Lee, J. I.; Ko, S.; Park, S. Highly Dispersive and Electrically Conductive Silver-Coated Si Anodes Synthesized Via a Simple Chemical Reduction Process. Nano Energy 2013, 2, 1271-1278.

74. Gu, M.; Ko, S.; Yoo, S.; Lee, E.; Min, S. H.; Park, S.; Kim, B.-S. Double Locked Silver-Coated Silicon Nanoparticle/Graphene Core/Shell Fiber for High-Performance Lithium-Ion Battery Anodes. J. Power Sources 2015, 300, 351-357.

75. Jiang, T.; Zhang, S.; Qiu, X.; Zhu, W.; Chen, L. Preparation and Characterization of Silicon-Based Three-Dimensional Cellular Anode for Lithium Ion Battery. Electrochem. Commun. 2007, 9, 930-934.

76. Zhang, Y. B.; Small, J. P.; Pontius, W. V.; Kim, P. Fabrication and Electric-Field-Dependent Transport Measurements of Mesoscopic Graphite Devices. Appl. Phys. Lett. 2005, 86.

77. Klein, C. A. Stb Model + Transport Properties of Pyrolytic Graphites. J. Appl. Phys. 1964, 35, 2947-\&.

78. Hwang, S. M.; Lee, H. Y.; Jang, S. W.; Lee, S. M.; Lee, S. J.; Baik, H. K.; Lee, J. Y. Lithium Insertion in Siag Powders Produced by Mechanical Alloying. Electrochem. Solid-State Lett. 2001, 4, A97-A100. 


\section{Table of Content}

Super-small silver nanoparticles with an average diameter of $2.9 \mathrm{~nm}$ are in situ synthesized and homogeneously embedded in the $\mathrm{Si} / \mathrm{C}$ nanohybrid, using epoxy resin as solvent and carbon source. Superior rate performance and improved cyclic stability are achieved with tiny amount of silver (2.59 \% by mass).
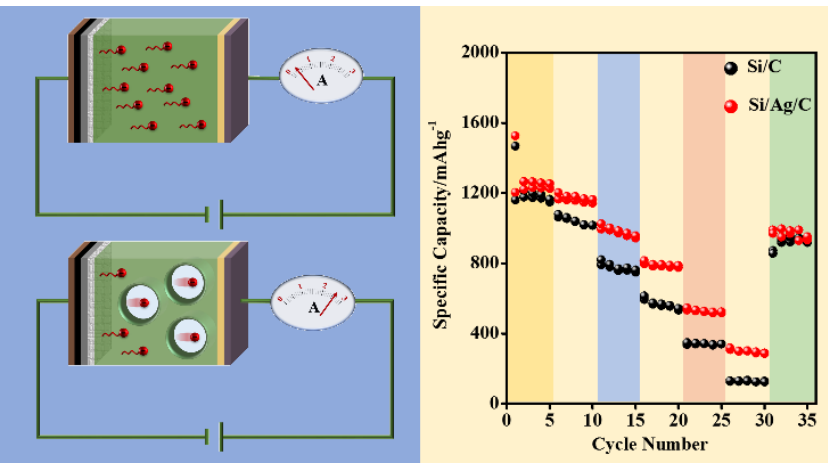